\title{
A probabilistic framework for comparison of dam breach parameters and outflow hydrograph generated by different empirical prediction methods
}

\author{
Ebrahim Ahmadisharaf ${ }^{1}$, Alfred J. Kalyanapu ${ }^{2}$, Brantley A. Thames ${ }^{3}$ and Jason Lillywhite ${ }^{4}$ \\ ${ }^{1}$ Postdoctoral Associate, Department of Biological Systems Engineering, Virginia Tech, Blacksburg, VA \\ 24061 \\ ${ }^{2}$ Assistant Professor, Department of Civil and Environmental Engineering, Tennessee Technological \\ University, Cookeville, TN 38505 \\ ${ }^{3}$ Civil Engineer, US Army Corps of Engineers, 801 Broadway, Nashville, TN 37203 \\ ${ }^{4}$ Water Resources Engineer, GoldSim Technology Group, 22500 SE $64{ }^{\text {th }}$ Place, Suite 240, Issaquah, WA \\ 98027
}

Submitted to: Environmental Modeling and Software

Date: September 26, 2016

\section{Corresponding Author:}

Dr. Alfred J. Kalyanapu

$$
\begin{gathered}
\text { Department of Civil and Environmental Engineering } \\
\text { Tennessee Technological University } \\
1020 \text { Stadium Drive, Box } 5015 \\
\text { Cookeville, TN 38505-0001, USA } \\
\text { Tel: }+1 \text { (931) } 3723561 \\
\text { Fax: }+1 \text { (931) } 3726239
\end{gathered}
$$

Email: $\underline{\text { akalyanapu@tntech.edu }}$

(C) 2016. This manuscript version is made available under the Elsevier user license http://www.elsevier.com/open-access/userlicense/1.0/ 


\begin{abstract}
This study presents a probabilistic framework to simulate dam breach and evaluates the impact of using four empirical dam breach prediction methods on breach parameters (i.e., geometry and timing) and outflow hydrograph attributes (i.e., time to peak, hydrograph duration and peak). The methods that are assessed here include MacDonald and Langridge-Monopolis (1984), Von Thun and Gillete (1990), Froehlich (1995) and Froehlich (2008). Mean values and percentiles of breach parameters and outflow hydrograph attributes are compared for hypothetical overtopping failure of Burnett Dam in the state of North Carolina, USA. Furthermore, utilizing the probabilistic framework, the least and most uncertain methods alongside those giving the most critical value are identified for these parameters. The multivariate analysis also indicates that lone use of breach parameters is not necessarily sufficient to characterize outflow hydrograph attributes. However, timing characteristic of the breach is generally a more important driver than its geometric features.
\end{abstract}

Keywords: Probabilistic dam breach model, Dam breach prediction, Uncertainty analysis, Multivariate analysis.

Software Availability: A GoldSim model that includes these four methods is provided with this paper. The model can be downloaded from: http://www.techwarms.org/software. It is an editable model, so users may change the inputs in the model to use in dam breach simulations for other dams.

\title{
1. Introduction
}

Dam breach is a serious concern all over the world due to its severe damages in the downstream areas. According to the National Inventory of Dams (NID), there are up to 15000 high-hazard potential dams in the US alone (US Army Corps of Engineers (USACE), 2013). A population growth of 130 million within the US by 2050, can lead to reclassifying many low or significant hazard dams to high-hazard potential as this population is expected to move into the undeveloped areas downstream of the aging dams (American Society of Civil Engineers (ASCE), 2013). According to the Association of State Dam Safety Officials (ASDSO), repair costs of US dams are estimated to be $\$ 57$ billion, and a $\$ 21$ billion investment is needed to repair aging high-hazard potential dams (ASCE, 2013). With the ASCE "D” grade rating of the nation's dams, the continued aging of US dams and the increase in the number of high-hazard potential dams, evaluation of the dam failure hazards is very crucial for proactive risk management and planning.

A dam may fail due to different causes with overtopping and piping as main failure modes (Singh and Scarlatos, 1988; USACE, 1997). Overtopping failure has been found to be the most crucial cause mainly with respect to time of failure (Tsakiris and Spiliotis, 2013). There are approximately 57000 dams in the US with overtopping hazard potential (Ralston, 1987) and it is also the leading reason of dam failure 
worldwide (Wu et al., 2011). Overtopping failure of a dam can be due to various reasons such as deficient design of outlet capacity, primary outlet failures, and large inflow events due to extreme rainfall. Global changes including climate change and urbanization have increased the risk of extreme hydrologic events such as flood (Gilroy and McCuen, 2012; Hirabayashi et al., 2013; Mallakpour and Villarini, 2015), which is likely to alter the dam overtopping risk. Hence, it is essential to analyze overtopping failure risk with more caution.

The first step in evaluation of dam failure flood risk is estimation of breach outflow (Ahmdisharaf et al., 2013). In spite of the recent research advances, breach prediction is still a substantial source of uncertainty in dam break risk assessment (Morris et al., 2009b). Dam breach outflow is often determined as a function of breach parameters, including geometry and timing. The prediction of breach characteristics is multifaceted because it needs the estimation of complex interactions between soil, water and structure (Wu et al., 2011). Breach features can be predicted through breach models, which are commonly classified into three groups: empirical, analytical, and physically-based (Morris et al., 2009b). This paper focuses on empirical methods. Until now, several empirical methods have been developed to estimate breach parameters, which mostly rely on simple regression analysis. Wahl $(1998 ; 2004)$ and Brunner (2014) provided an excellent literature review on prediction methods in this context. In general, no single breach model can be recommended (Morris, 2000) and thus it is required to estimate breach parameters based on different available approaches. There have been few studies on comparison of breach prediction methods such as Wahl (2004), Gee and Brunner (2007) and Yochum et al. (2008). All of these studies have employed a deterministic framework and not incorporated data or model uncertainties.

Like any physically based phenomena, empirical methods to predict breach geometry and timing, have uncertainty and thus influence the estimated breach outflow. This uncertainty is attributed to various factors, including: poor documentation of historical failure events; lack of knowledge; inherent variation in the erodibility of cohesive materials; the effects of variability of embankment design; configuration; and geometry (Wahl et al., 2008; Wu et al., 2011). Bearing in mind these various sources of uncertainty and huge damages of dam break events, it is very crucial to analyze the uncertainty of breach parameters for reliable outflow estimation.

One of the complexities in quantifying the uncertainty of the breach outflow hydrograph is that the outflow is affected by multiple uncertain variables, in which the nature and range of their uncertainties are not independent (Zhong et al., 2011). There have been few studies that analyzed the uncertainties of breach parameters. Wahl (2004) evaluated several empirical breach prediction methods and their uncertainties in terms of average breach width, formation time and peak outflow. In that study, the methods were applied on a hypothetical erosion seepage failure and suggested breach parameter ranges were presented. However, a similar study for overtopping is not found in the literature. Additionally, 
uncertainties in breach hydrograph attributes such as time to peak and duration, which are crucial in determining the time-variant flood parameters (e.g., velocity, duration and arrival time), the worst flooding scenario (e.g., estimation of evacuation ability and population at risk (PAR)) (Morris, 2005; Dang et al., 2011; Qi and Altinakar, 2011a; 2011b; 2012; Ahmadisharaf et al., 2015), have not been assessed. The sole estimation of peak outflow for assessing downstream flood risk can be another source of uncertainty, as it requires a breach hydrograph, which should be fitted to the estimated peak that would likely increase the flow computation error (Morris et al., 2009b). It is also noted through the literature review that uncertainty analyses have been typically performed deterministically. Deterministic frameworks have inherent limitations and may not reveal the worst case scenario and thus may not be an appropriate strategy for uncertainty analysis. Furthermore, uncertainty analysis by using a deterministic framework may not adequately reveal the inter-relationships between the independent variables (Peng and Zhang, 2012). Applying probabilistic frameworks are more desirable, in which the risk is quantified and the impact of various uncertainties is incorporated and uncertainty of input parameters is propagated to the output by using probability distributions (Zhong et al., 2011). Froehlich (2008) stated the need for thorough uncertainty analysis of breach parameters by incorporating their inherent randomness. Monte Carlo (MC) sampling strategies and specifically Latin Hypercube sampling (LHS) (McKay et al., 1979) are valuable tools in this context. Therefore, probabilistic dam breach methods are needed to better understand the risks and to evaluate the uncertainty of the breach outflow hydrograph.

One concern about using a probabilistic dam breach model is the high computational time needed by flood models (in particular, two-dimensional models) to route multiple breach hydrographs through the downstream valley (Morris, 2005). However, recent advances in computational capabilities of flood models with tremendous speedup (e.g., Flood2D-GPU by Kalyanapu et al. (2011)) can assist modelers in efficiently using probability-based analyses. Considering these advances in flood modeling, breach outflow hydrograph estimation needs to be improved by incorporating the uncertainties using probabilistic frameworks.

This study presents a probabilistic framework to evaluate the impact of employing different dam breach prediction methods on breach timing and geometry as well as outflow hydrograph. The unique aspects of this research are: i) application of a probabilistic dam breach framework for comparison of different breach prediction methods; ii) evaluation of different breach prediction methods on a hypothetical overtopping failure; iii) analysis of the uncertainties of all the breach outflow hydrograph attributes (including time to peak and duration) and not only peak; v) multivariate analysis to analyze the sensitivity of outflow hydrograph attributes to breach parameters. Four empirical breach prediction methods are assessed here, including MacDonald and Langridge-Monopolis (1984), Von Thun and Gillete (1990), Froehlich (1995) and Froehlich (2008). A probabilistic LHS-based framework is employed 
to propagate the uncertainty of inputs to outputs. Resulting mean values and percentiles are compared for breach parameters including average breach width and formation time and hydrograph attributes. In addition, the least and most uncertain methods alongside those giving the most critical value are identified for these parameters. Multivariate analysis is finally carried out to investigate the sensitivity of breach hydrograph attributes to average breach width, formation time and bottom elevation of final breach. This investigation is illustrated through the hypothetical overtopping failure of Burnett Dam, which is one of the high-hazard potential dams in the state of North Carolina.

\section{Methodology}

The methodology section is organized into the following sub-sections: 1) dam breach prediction methods: description of the four methods used here to predict breach geometry and timing; 2) dam breach outflow equations: description of the methodology applied to determine dam breach outflow hydrograph; 3 ) development of the probabilistic dam breach model: description of the probabilistic dam breach model development, characterizing uncertainty of input elements and uncertainty propagation; and 4) comparison metrics: description of the measures used to compare the results of breach parameters and outflow hydrograph.

\subsection{Dam Breach Prediction Methods}

The following sub-section describes the four chosen dam breach prediction methods. It is to be noted that these four methods are chosen as they suggest equations for both average breach width and formation time, and are often applied in-practice (Brunner, 2014).

\subsubsection{MacDonald and Langridge-Monopolis (1984)}

MacDonald and Langridge-Monopolis (MLM) in 1984 studied 42 dam failure events and proposed equations to estimate eroded volume and breach formation time for earthfill and non-earthfill dams. They reported a good correlation between volume of eroded material and a parameter called breach formation factor $(B F F) . B F F$ is the product of the outflow volume of water and the height of the water above the breach base at time of failure. The equation series can be written as:

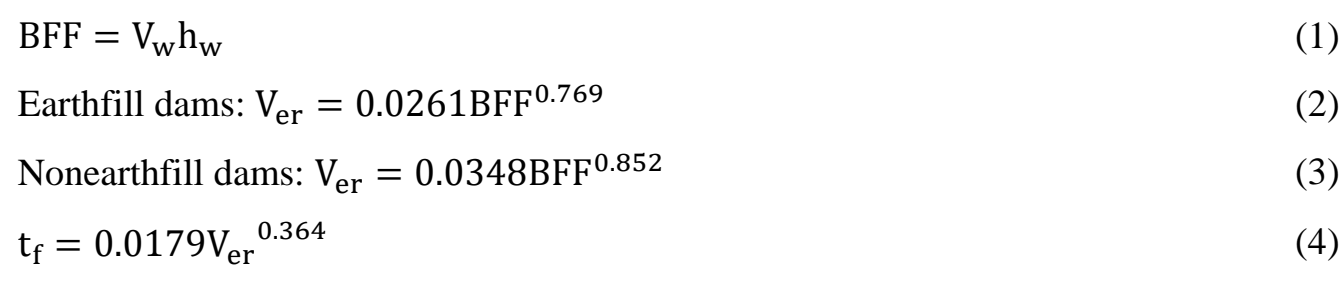

where, $h_{w}$ is depth of water above breach at time of failure in meters, $V_{e r}$ is volume of embankment material eroded in cubic meters, $V_{w}$ is the volume of water that passes through the breach in cubic meters and $t_{f}$ is breach formation time in hours. The equation for breach formation time is an envelope of the historical earthfill dam failures, which implies that it overestimates the actual breach time for homogenous earthfill dams (Gee and Brunner, 2007). 
Although the MLM method does not suggest a regression equation for average breach width, by assuming a trapezoidal breach, the corresponding width of $V_{e r}$ can be written as (Washington State Department of Ecology, 2007):

$$
\begin{aligned}
& \mathrm{B}_{\mathrm{f}}=\frac{\mathrm{V}_{\mathrm{er}}-\mathrm{h}_{\mathrm{b}}^{2}\left(\mathrm{Cm}+\frac{\mathrm{h}_{\mathrm{b}} \mathrm{mz}_{3}}{3}\right)}{\mathrm{h}_{\mathrm{b}}\left(\mathrm{C}+\frac{\mathrm{mz}_{3}}{2}\right)} \\
& \mathrm{B}_{\mathrm{avg}}=\mathrm{B}_{\mathrm{f}}+\mathrm{mh}_{\mathrm{b}}
\end{aligned}
$$

where, $V_{e r}$ is same as mentioned earlier, $m$ is breach side slope $(\mathrm{H}: \mathrm{V}), h_{b}$ is height of breach in meters, $B_{f}$ is final breach width in meters, $C$ is dam crest width in meters, $z_{3}$ is the summation of slope $(\mathrm{H}: \mathrm{V})$ of upstream and downstream faces of dam, and $B_{\text {avg }}$ is average width of final breach in meters. MLM suggested a breach side slope of $0.5(\mathrm{H}: \mathrm{V})$.

\subsubsection{Von Thun and Gillette (1990)}

Von Thun and Gillette (VTG) (1990) studied 57 dam failure events and proposed equations to estimate average breach width and formation time. VTG found wider breaches produced by larger reservoir volumes at a given height. The equation series can be written as:

$$
\mathrm{B}_{\mathrm{avg}}=2.5 \mathrm{~h}_{\mathrm{w}}+\mathrm{B}
$$

Highly erodible: $\mathrm{t}_{\mathrm{f}}=0.015 \mathrm{~h}_{\mathrm{w}}$

Erosion resistant: $\mathrm{t}_{\mathrm{f}}=0.020 \mathrm{~h}_{\mathrm{w}}+0.25$

where, $t_{f}, B_{\text {avg }}$ and $h_{w}$ are the same as defined for the MLM method and $B$ is offset factor, which is a function of reservoir volume and can be determined based on Table 1. By using the offset factor, it accounts for reservoir volume.

Table 1. Offset factor determination in VTG method (derived from Von Thun and Gillette (1990))

\begin{tabular}{cc}
\hline Reservoir Size $\left(\mathbf{m}^{\mathbf{3}}\right)$ & B $(\mathbf{m})$ \\
\hline$<1.23 * 10^{6}$ & 6.1 \\
$1.23 * 10^{6}-6.17 * 10^{6}$ & 18.3 \\
$6.17 * 10^{6}-1.23 * 10^{7}$ & 42.7 \\
$1.23 * 10^{7}<$ & 54.9 \\
\hline
\end{tabular}

VTG also developed the following equations for breach formation time based on datasets of average lateral erosion rates:

Highly erodible: $t_{f}=\frac{B_{a v g}}{4 h_{w}+61}$

Erosion resistant: $t_{f}=\frac{B_{\text {avg }}}{4 h_{w}}$ 
where, $t_{f}, B_{\text {avg }}$ and $h_{w}$ are the same as defined for the MLM method. Here, Equation 11 is used for estimating breach formation time. VTG recommended a typical breach side slope value of $1(\mathrm{H}: \mathrm{V})$. Alternatively, VTG stated that slopes of 0.5 or $0.33(\mathrm{H}: \mathrm{V})$ may be more suited to dams with cohesive shells or very wide cohesive cores.2.1.3.

\subsubsection{Froehlich (1995)}

Froehlich (1995) (F95) studied 63 dam failure events and proposed equations to estimate average breach width and formation time. The equations are as follows:

$$
\begin{aligned}
& \mathrm{B}_{\mathrm{avg}}=0.1803 \mathrm{~K}_{\mathrm{O}} \mathrm{V}_{\mathrm{w}}{ }^{0.32} \mathrm{~h}_{\mathrm{b}}{ }^{0.19} \\
& \mathrm{t}_{\mathrm{f}}=0.00254 \mathrm{~V}_{\mathrm{w}}{ }^{0.53} \mathrm{~h}_{\mathrm{b}}{ }^{-0.9}
\end{aligned}
$$

where, $B_{a v g}, h_{w}, h_{b}$ and $V_{w}$ are the same as defined for the MLM method and $K_{O}$ is overtopping coefficient, which is 1.4 for overtopping and 1.0 for piping. F95 recommended a typical breach side slope value of $1.4(\mathrm{H}: \mathrm{V})$ for overtopping failure and $0.9(\mathrm{H}: \mathrm{V})$ for other types.

\subsubsection{Froehlich (2008)}

Froehlich (2008) (F08) studied 74 dam failure events and proposed equations to estimate time to failure and average breach width. The equation series can be written as:

$$
\begin{aligned}
& \mathrm{B}_{\mathrm{avg}}=0.27 \mathrm{~K}_{\mathrm{O}} \mathrm{V}_{\mathrm{w}}{ }^{0.32} \mathrm{~h}_{\mathrm{b}}{ }^{0.04} \\
& \mathrm{t}_{\mathrm{f}}=0.0176 \sqrt{\frac{\mathrm{V}_{\mathrm{w}}}{\mathrm{gh}_{\mathrm{b}}{ }^{2}}}
\end{aligned}
$$

where, $B_{a v g}, h_{w}, V_{w}$ and $h_{b}$ are the same as defined for the MLM method, $g$ is acceleration of gravity $\left(\mathrm{m} / \mathrm{s}^{2}\right)$ and $K_{O}$ is same as F95 but value of 1.3 is suggested for overtopping rather than the value of 1.4. F08 recommended a typical breach side slope value of $1(\mathrm{H}: \mathrm{V})$ for overtopping failure mode and 0.7 for other modes.

\subsection{Dam Breach Outflow Equations}

A breach outflow equation using trapezoidal breach cross-section is applied in this study to simulate dam breach outflow. The model employs breach geometry and timing based on the four dam breach prediction methods as input parameters. Level pool routing is used to route the inflow through the reservoir. At each time step, instantaneous water surface elevation is computed based on the corresponding volume of water behind the reservoir, which is derived from linear interpolation of the values of stage-storage table. Euler integration technique is used to numerically solve the routing problem. A trapezoidal breach cross-section is assumed as it is the most frequent final shape in historical failures (MacDonald and LangridgeMonopolis, 1984; Wahl, 1998; Xu and Zhang, 2009) and often applied in practice (Froehlich, 2008). Alternatively, trapezoidal shape has also been argued to be a valid option during the breach development 
(Mohamed et al., 2002; Morris, 2005). It is to be noted that other breach shapes such as rectangular and triangular can be set in the model by changing the side slope or bottom width of the trapezoidal shape.

The instantaneous breach outflow is determined through a weir equation following the methodology of the USACE's HEC-RAS model. A weir coefficient of 1.44 is used here based on Brunner (2010) recommendation for metric unit system. It is to be noted that the model assumes free flow condition and does not account for submergence effects.

The instantaneous breach parameters are function of breach progression. The model is capable of accounting for any desired progression rate (linear, sine wave or user-defined). However, linear progression is used for this study application as it is one of the most commonly used that can describe the major portion of breach development well (Froehlich, 2008). By determination of the breach progression rate, instantaneous dimensions of the trapezoidal breach can be calculated. Furthermore, the model is capable of considering various types of failure triggers such as water surface elevation and specified initiation time.

\subsection{Development of a Probabilistic Dam Breach Model}

A probabilistic dam breach model is developed in GoldSim ${ }^{\circledR}$ environment. GoldSim ${ }^{\circledR}$ is a dynamic simulation software with applications ranging from water resources management to financial predictions and provides a versatile user-friendly graphical user interface (GUI) for probabilistic modeling. First, a deterministic dam breach model is developed in GoldSim ${ }^{\circledR}$ and is validated with three dam overtopping events. The validated deterministic model is then extended to a probabilistic model, and average breach width, breach formation time, bottom elevation of final breach $\left(h_{f}\right)$ and reservoir inflow are considered as stochastic parameters. Each stochastic element is characterized by a probability density function (PDF) as it is the most perfect uncertainty characterization approach (Tung, 2011).

To select the suitable PDFs for these factors, the following assumptions are made. A triangular PDF is applied to breach formation time and average breach width, in which mode values are determined based on the aforementioned breach prediction methods (Equations 4-15). The minimum and maximum values for three of the prediction methods, including MLM, VTG and F95 are taken from the existing uncertainty estimation by Wahl (2004). Wahl (2004) applied a robust estimator of variance, the median absolute deviation (MAD), to determine the uncertainty bands of the methods. The method analyzes the statistical properties of the errors produced by each prediction method. This includes the calculation of mean and median of the errors alongside their absolute deviation from the median. Furthermore, the outlier exclusion algorithm is employed to filter the dataset in preparation for uncertainty quantification. For consistency reasons, the same methodology as Wahl (2004) is used to determine the uncertainty bands of F08 method. It is notable that the same approach was applied by Pierce et al. (2010) and Thornton et al. (2011) in uncertainty analysis of dam breach methods. 
To evaluate the suitability of the selected PDFs, the relative frequency of the occurrence of the observed breach parameters for Wahl (1998) dam failure database is calculated. The calculated frequencies are then compared with the statistics (minimum, maximum and mode) of the selected PDF for each breach parameter (i.e., triangular for formation time and average breach width and uniform for bottom height of the final breach).

Even though methods to estimate breach formation time and average breach width exist, there is no specific approach to determine bottom elevation of final breach. Therefore, it is considered an uncertain parameter here. To determine the statistical characteristics of this parameter, the historical failure database of Wahl (1998) is statistically analyzed. The ratio of breach to dam height for all presented failures is computed. A total of 53 failures (both overtopping and piping) exist in the database, in which both dam and breach height are presented. The analysis revealed that the ratio varies between 0.3 to 1.22. It was also noted that the breach most frequently matched the height of the dam (i.e., breach to dam height ratio of 1). Thus, a triangular PDF is used to represent the bottom elevation of final breach with minimum, maximum and mode value of $-0.22(1-1.22=-0.22), 0.7(1-0.3=0.7)$ of the dam height and zero $(1-1=0)$, respectively.

The last stochastic input of the model, reservoir inflow, is characterized with a normal PDF. The distribution variables are determined based on the instantaneous flow data statistics of an upstream gaging station. Minimum, mean, maximum, standard deviation and autocorrelation coefficient are determined based on the recorded flow data. To avoid unrealistic inflow hydrographs, the stochastic element is selfcorrelated in GoldSim ${ }^{\circledR}$ using Gaussian copula methodology. A copula is a joint distribution that describes dependences between random variables independent of their marginal distribution (Nelsen, 2007). Gaussian copula is constructed from a multivariate normal PDF and generates values where the correlation between variables is stronger towards the middle of the distributions than the tails. Applying the aforementioned PDF, results in a wide variety of hydrograph time series and thus various reservoir inflow scenarios are taken into consideration.

To explore the dependencies between the breach parameters, the Wahl (1998) failure database is employed. The correlation between formation time with bottom elevation of final breach and average breach width, is determined. The analysis reveals that there is a weak correlation between the aforementioned parameters and thus no correlation is used.

LHS technique with random point in strata is employed in this study for propagation of uncertainty. At each realization, a breach hydrograph is generated by producing a random value for each stochastic element based on the corresponding PDF. As the standard MC method generates pseudo random numbers, a sampling efficiency technique is usually suggested (Janssen, 2013). Here, LHS is employed due to its potential in outperforming the sampling efficiency (Helton and Davis, 2003). It is commonly 
preferred to the standard MC as smaller sample size is required and computational efficiency will be achieved accordingly (Melching, 1995; Hall et al., 2005; Janssen, 2013). This benefit can be utilized in dam break studies where several uncertain variables exist and high number of realizations are required. LHS was successfully employed in dam break analysis studies such as Kwon and Moon (2006) and Kuo et al. (2007).

Using the selected PDFs and the uncertainty propagation method, the probabilistic model is then validated against a historical failure case. First, it is tested whether the observed peak (the entire hydrograph is not often reported for the historical failure cases) falls within the $90 \%$ confidence interval of the predicted peak by the probabilistic model. Xu and Zhang (2009) used a similar approach to validate their developed breach model against the historical dam failures. Second, the reported reservoir volume is compared with those from the simulations (the same analysis cannot be conducted for the outflow since the hydrograph is not often reported). The average relative interval length (ARIL) measure (Jin et al., 2010 ) is utilized to test the model efficiency. The measure can be computed via the following equation:

$$
\text { ARIL }=\frac{1}{N} \sum_{i=1}^{N} \frac{x_{U i}}{x_{O i}}-\frac{x_{L i}}{x_{O i}}
$$

where $N$ is the number of time steps; $x_{L i}$ and $x_{U i}$ are the lower and upper limits at time step $i$, respectively; and $x_{O i}$ is the observed volume at this time step. The greater the ARIL value the more the uncertainty and vice versa. Upper and lower limits are determined based on the statistical analysis provided by GoldSim ${ }^{\circledR}$. A $p^{\text {th }}$ percentile time series is a time series in which the reservoir volume values are not exceeded in $p^{\text {th }}$ of the LHS realizations. The minimum and maximum refer to the $0^{\text {th }}$ and $100^{\text {th }}$ percentiles, respectively. Here, the $5^{\text {th }}$ and $95^{\text {th }}$ percentiles are used as the lower and upper limits (Beven and Binley, 1992). A similar approach has been used by Dotto et al. (2012) for uncertainty analysis of an urban stormwater model and Ahmadisharaf (2016) for uncertainty quantification of the flood consequences.

\subsection{Comparison Metrics}

The results of five parameters, average breach width, formation time, time to peak, hydrograph duration and peak outflow, produced by the four breach prediction methods are compared. The comparison is conducted in four phases:

i. Comparison of mean value and percentiles: Mean value along with $5^{\text {th }}$ and $95^{\text {th }}$ percentiles of average breach width, formation time, time to peak, hydrograph duration and peak estimated by the four prediction methods, are compared. Moreover, the most and the least uncertain prediction methods in terms of outflow hydrograph attributes are determined by comparing the ratio of lower and upper limits to the mean values. Here, the $5^{\text {th }}$ and $95^{\text {th }}$ percentiles are used as the lower and upper limits 
(Beven and Binley, 1992). The difference between these two ratios is used as the uncertainty band. In other words, the following equation is used to determine the uncertainty band:

$$
\mathrm{U}=\frac{\mathrm{X}_{95}}{\overline{\mathrm{x}}}-\frac{\mathrm{X}_{5}}{\overline{\mathrm{x}}}
$$

where, $U$ is the uncertainty band; $x_{5}$ and $x_{95}$ are the $5^{\text {th }}$ and $95^{\text {th }}$ percentiles, respectively; and $\bar{x}$ is the mean value. A breach method with a higher $U$ value is more uncertain. The uncertainty band is similar to ARIL, which was mentioned earlier in the validation of the probabilistic model. However, an observed value was used in the denominator for normalization since no observation is available in the demonstration case study (a hypothetical dam failure is analyzed). It is notable that the uncertainty bands of the two breach parameters (average breach width and formation time) is not determined by using this method. Rather, they are determined following Wahl (2004) methodology, which was discussed in the previous subsection.

ii. Multivariate analysis of the results: For each breach prediction method, a multivariate analysis is carried out to investigate the relationship between the breach outflow hydrograph attributes (time to peak, hydrograph duration and peak) and breach parameters (average breach width, formation time and bottom elevation of final breach). The metrics used by GoldSim ${ }^{\circledR}$ for multivariate analysis are importance measure, standardized version of the measure introduced by Saltelli and Tarantola (2002), and coefficient of determination $\left(R^{2}\right)$. The importance measure represents the fraction of the output variance that is explained by an input parameter. On the other hand, $R^{2}$ represents the fraction of the output variance that can be described through a linear relationship to the input parameter(s). While $R^{2}$ can only identify the linear relationship, importance measure can reveal nonlinear non-monotonic relationships as well. Both measures vary between 0 and 1 , and the closer the value to 1 , the stronger the relationship between the input and output. The values of the two comparison metrics are compared to investigate the difference of the four breach prediction methods in terms of the relationship between breach parameters and outflow hydrograph attributes.

\section{Case Studies}

This section presents the case studies that are used in model validation and illustration phases. Three case studies are used to validate the deterministic model and a case study is applied to illustrate the probabilistic model. The cases are described in-detail in the two following sub-sections.

\subsection{Validation Case Studies}

Three case studies are used to validate the deterministic dam breach model, namely: 1) hypothetical dam presented in International Commission on Large Dams (ICOLD) benchmark study; 2) Banqiao Dam in China; and 3) US Department of Agriculture (USDA) - Agricultural Research Service (ARS) laboratory 
test. The first two dams are large based on ICOLD classification while the third case is a small dam according to the classification by USACE (1979).

The first case is overtopping failure of a hypothetical dam near populated region as developed by the ICOLD Benchmarking Workshop on Numerical Analysis of Dams (Thames and Kalyanapu, 2013). The dam has height of $61 \mathrm{~m}$ and reservoir capacity of 38.3 million $\mathrm{m}^{3}$.The second validation case is catastrophic failure of the Banqiao Dam in China in 1975. The dam was $24.5 \mathrm{~m}$ high with reservoir capacity of 492 million $\mathrm{m}^{3}$, crest of $2020 \mathrm{~m}$ long and $6 \mathrm{~m}$ wide. The dam was overtopped because of excessive inflows due to high rainfall in August 1975.

The last validation case is an outdoor laboratory test performed by USDA-ARS in June 1999 in the state of Oklahoma, US. The dam was $2.2 \mathrm{~m}$ high with reservoir capacity of $5269 \mathrm{~m}^{3}$ and crest of $4.6 \mathrm{~m}$ wide. The test is identified in Hanson et al. (2005) as embankment 1 constructed from soil 1.

\subsection{Demonstration Case Study}

The validated deterministic model is then extended to probabilistic and is used to illustrate the impact of the four breach prediction methods using a hypothetical overtopping failure of Burnett Dam (also known as North Fork Dam) located in Buncombe County, state of North Carolina, USA. The dam is located in the Swannanoa River watershed, which is a part of the larger French Broad River basin. Fig. 1 shows the location map of the dam. Constructed in 1954, the dam is earthfill with structural height of 40.7 $\mathrm{m}$, crest length of $399.0 \mathrm{~m}$ and width of $7.6 \mathrm{~m}$, reservoir volume of 25.5 million $\mathrm{m}^{3}$ at top of dam elevation and drainage area of $52.1 \mathrm{~km}^{2}$. The spillway crest elevation is $787.3 \mathrm{~m}$ (above mean sea level), and the total spillway capacity at maximum pool level is $764.6 \mathrm{cms}$. The dam is classified high-hazard potential as several municipal facilities are located at the toe of the dam and several houses are placed along the downstream area. The study by Ahmadisharaf and Kalyanapu (2015) showed that there is an increasing trend in the dam overtopping risk. Regarding the size, the dam is classified as "large" according to both the ICOLD and USACE (1979). The main dam is sufficiently protected by riprap and shows no signs of peripheral erosion. Furthermore, the embankment core material is impervious, which implies the clay content is high. Based on Xu and Zhang (2009), clay soils are attributed with low to medium erodibility. Considering all these points, the dam is considered erosion resistant (for VTG application). 


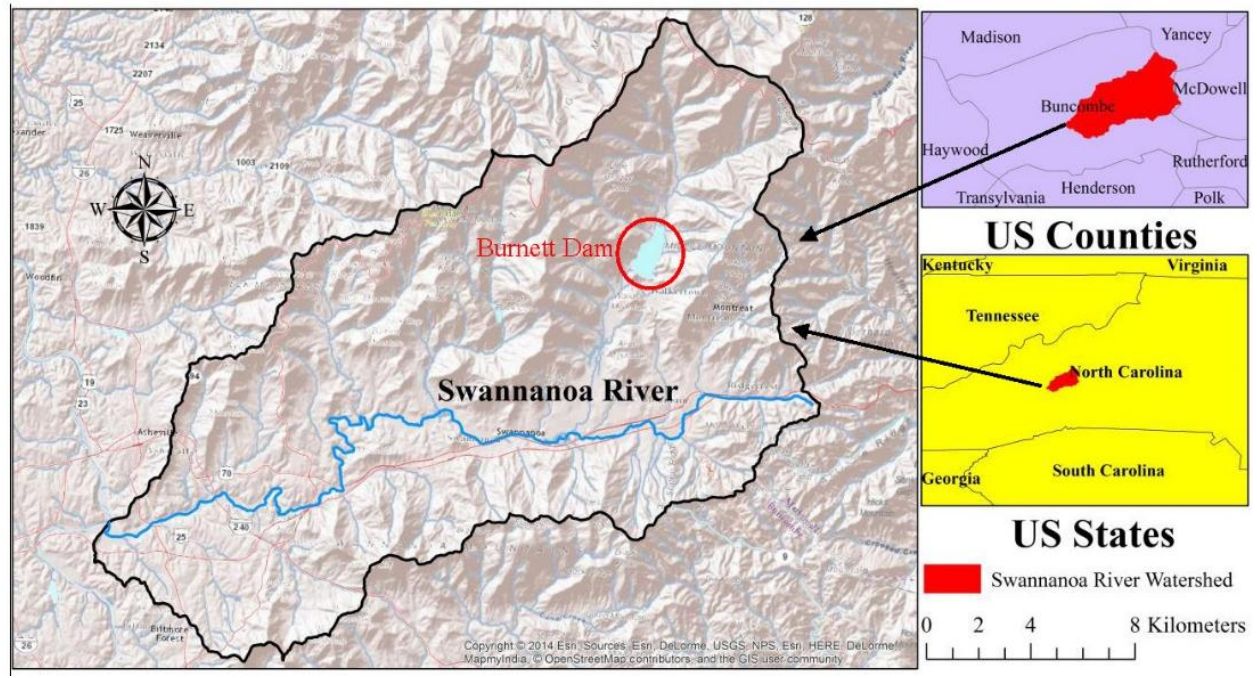

Fig. 1. Location map of Burnett Dam

\section{Results and Discussion}

This section presents the application of the probabilistic dam breach model and comparative analysis of the breach parameters and outflow hydrographs produced by the four prediction methods. It is organized in the following sub-sections: 1) dam breach model validation; 2) uncertainty quantification of the breach parameters (geometry and timing); 3) probabilistic model application; and 4) comparison of the results.

\subsection{Dam Breach Model Validation}

As mentioned earlier, a deterministic dam breach model in GoldSim ${ }^{\circledR}$ is developed and first validated against three overtopping failure events. For the simulations of the validation case studies, Nash-Sutcliffe Efficiency (NSE) (Nash and Sutcliffe, 1970), $R^{2}$ as well as peak flow $\left(F_{Q}\right)$ and travel time $\left(F_{T}\right)$ accuracy measures (Schubert and Sanders, 2012) are used to measure the model performance in terms of outflow hydrograph and reservoir volume. It is to be mentioned that as the outflow hydrograph is not available for the historical failure case (i.e., case 2), only peak and time to peak parameters are compared in tandem with the reservoir volume.

\subsubsection{ICOLD Hypothetical Dam}

As the dam is hypothetical and there is no breach data available, an equivalent HEC-RAS model is built, and the simulation results are compared against it. Both HEC-RAS and GoldSim ${ }^{\circledR}$ models are implemented by using both linear and sine wave progressions. NSE of $97.2 \%$ is computed for both linear and sine wave progressions, and $R^{2}$ of $97.3 \%$ and $97.2 \%$ is computed for linear and sine wave progressions, respectively. Peak outflow calculated by the GoldSim ${ }^{\circledR}$ model matches very close to HECRAS results with a $F_{Q}$ of 1.004 and 0.993 for linear and sine wave progressions, respectively. Time to peak calculated by the GoldSim ${ }^{\circledR}$ model slightly overpredicts HEC-RAS values by $3.8 \%\left(F_{T}\right.$ of 1.038$)$ and $2.8 \%\left(F_{T}\right.$ of 1.028$)$ for linear and sine wave progressions, respectively. In addition to the breach outflow 
hydrograph, the model efficiency is further evaluated in terms of reservoir volume against HEC-RAS. NSE of $99.8 \%$ and $99.7 \%$ is computed for linear and sine wave progressions, respectively, and $R^{2}$ of 99.8 is computed for both linear and sine wave progressions. This analysis clearly shows that the GoldSim ${ }^{\circledR}$ model predicts dam breach very similar to HEC-RAS in terms of breach outflow hydrograph and reservoir volume and therefore can be deemed appropriate to be used in the study.

The slight difference between HEC-RAS and GoldSim ${ }^{\circledR}$ models is attributed to the difference in their numerical integration methods for solving reservoir level pool routing equations. As a result, the HECRAS and GoldSim ${ }^{\circledR}$ implementations do not have a perfect agreement. GoldSim ${ }^{\circledR}$ employs Euler integration in the reservoir element, which is forward in time and the outflow is computed in series based on the reservoir stage. On the other hand, HEC-RAS solves a centered difference formulation (Brunner, 2010). The outflow at time $t+1$ is incorporated into the computation for storage at time $t+1$ (more in parallel). This results in the use of different head values for the weir-type dam breach equation, which results in slightly different evolution of storage values.

\subsubsection{Banqiao Dam}

The data for this case is obtained from the Center for Energy Advancement through Technological Innovation (CEATI, 2008) for the Dam Safety Interest Group (DSIG) project. A breach measuring up to $29.5 \mathrm{~m}$ in height was formed as a result of this failure. This was simulated in GoldSim for a simulation duration of about 3 days and specified breach initiation time is used as the failure trigger. Breach progression rate time series are user-defined and running the GoldSim ${ }^{\circledR}$ model takes $3.6 \mathrm{~s}$ in this case. Fig. 2 shows the predicted outflow hydrograph by the GoldSim ${ }^{\circledR}$ model alongside the reported peak of the Banqiao Dam failure. The GoldSim ${ }^{\circledR}$ model predicts a peak outflow of $76260 \mathrm{cms}$, which is very close to the reported peak value of $78100 \mathrm{cms}\left(F_{Q}\right.$ of 0.976$)$. An $F_{T}$ of 0.985 is also estimated, which reveals the model capability in estimating the time to peak. It is notable that the reported values are subject to uncertainty and it is because during failure events, there are usually no reliable gauge data available and the flows are back-calculated from the reservoir stage time history and the stage-storage relation. In addition to the breach outflow, the model efficiency is also tested in terms of reservoir volume time series acquired from CEATI. Fig. 3 shows the predicted reservoir volume by the GoldSim ${ }^{\circledR}$ model alongside the reported values of the Banqiao Dam failure. NSE of $77.0 \%$ and $R^{2}$ of $77.7 \%$ are computed, which reveal good performance of the GoldSim ${ }^{\circledR}$ model. 


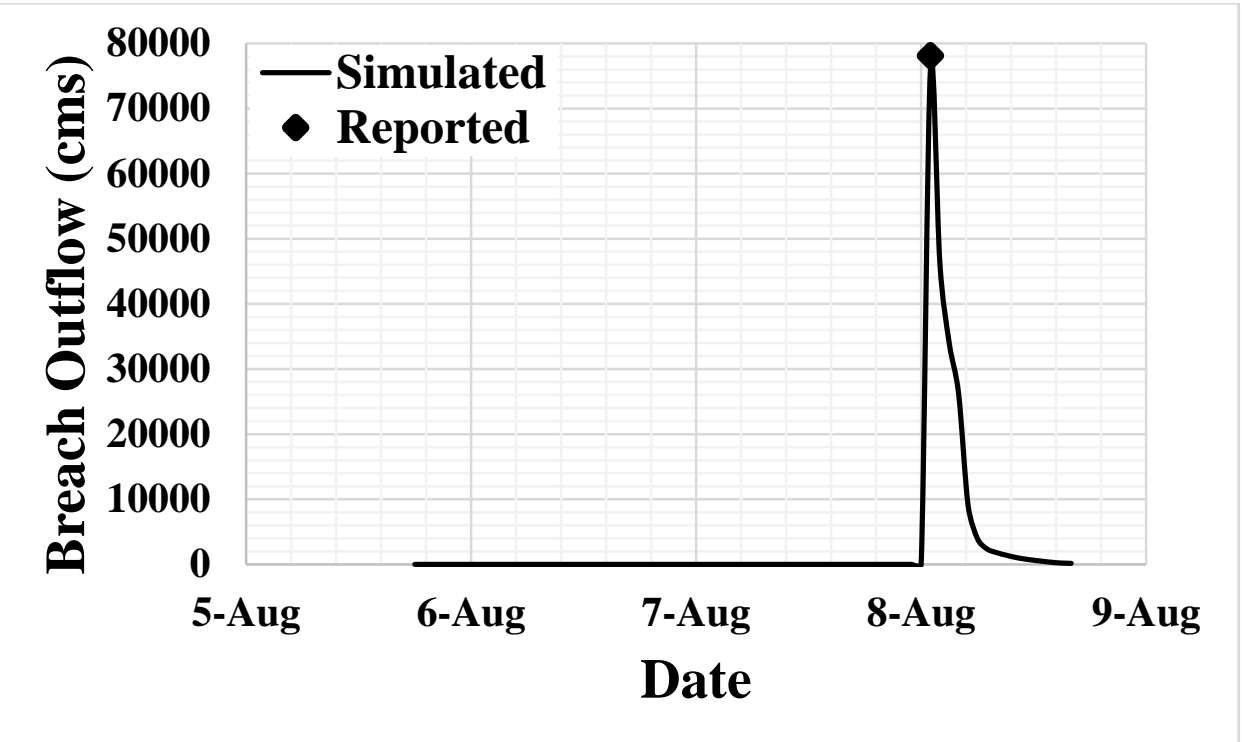

Fig. 2. Predicted breach hydrograph along with the reported peak outflow for Banqiao Dam failure

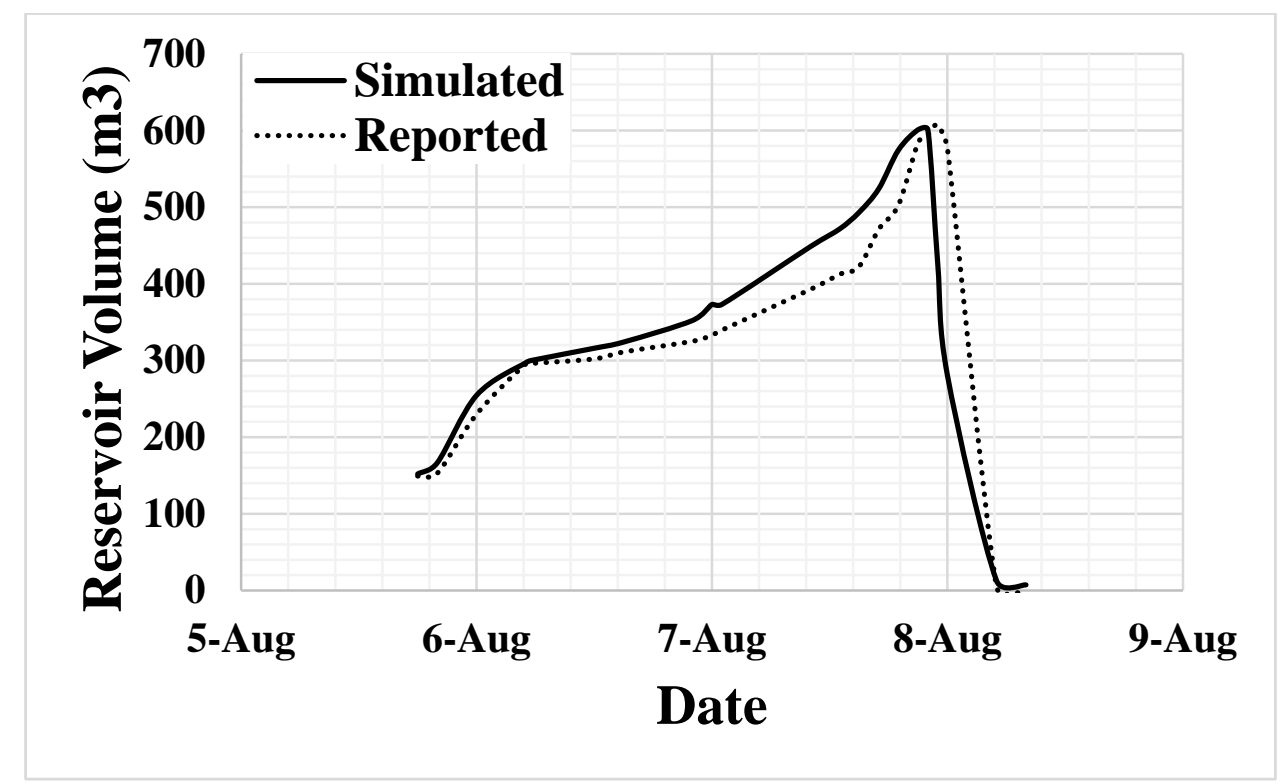

Fig. 3. Predicted and reported reservoir volume for Banqiao Dam failure

\subsubsection{USDA-ARS laboratory test}

The breach data are extracted from the dam failure database by CEATI (2008). Simulation duration is 154 min and the failure is triggered based on a specified breach initiation time. Breach progression rate time series are taken from the CEATI (2008). The model computational time is $0.3 \mathrm{~s}$ in this case. Fig. 4 shows the predicted and observed outflow hydrograph for this failure test. Although the GoldSim ${ }^{\circledR}$ model predicts the time to peak desirably ( $F_{T}$ of 0.870$)$, peak outflow of $4.0 \mathrm{cms}$ is estimated $\left(F_{Q}\right.$ of 0.610$)$, 
which is not desirable. This difference might stem from the model simplifications in simulating breach, which is likely to affect the modeling results of smaller dams more significantly. The model employs level pool routing technique, which is not well suited to the narrow reservoirs where there is high water surface slope upstream of the dam (the water surface is always horizontal with level pool routing). In this situation, full dynamic wave might be a more appropriate technique (Brunner, 2014). Moreover, the model is not capable of simulating the headcut migration, which is the dominant erosion process in this case and thus neglecting it might significantly affect the modeling results. Ultimately, the model cannot account for the downstream submergence effects, which is plausible to affect the breach outflow in this test. In addition to these points, there is measurement uncertainty in this experiment because first, the instantaneous breach values were determined by photographic analysis, which requires human judgment. The oscillation in the observed breach widths once the breach completely forms, is an indicator of this uncertainty. Second, the reported outflow hydrograph was not determined through measurements and rather, it was back-calculated by using reservoir volumetric balance. Alongside the comparison of breach outflow hydrograph, the observed reservoir volume time series is compared with model predictions. Fig. 5 shows the predicted and observed reservoir volume for this test. NSE of $71.9 \%$ and $R^{2}$ of $82.1 \%$ are computed which reveal good performance of the GoldSim ${ }^{\circledR}$ model. It is worth mentioning that the plots given here are based on the CEATI (2008) set, which differs from Hanson et al. (2005) in definition of elapsed time. The CEATI (2008) set includes reservoir filling, while Hanson et al. (2005) starts when water crests the embankment test section (after about 50 minutes of reservoir filling time).

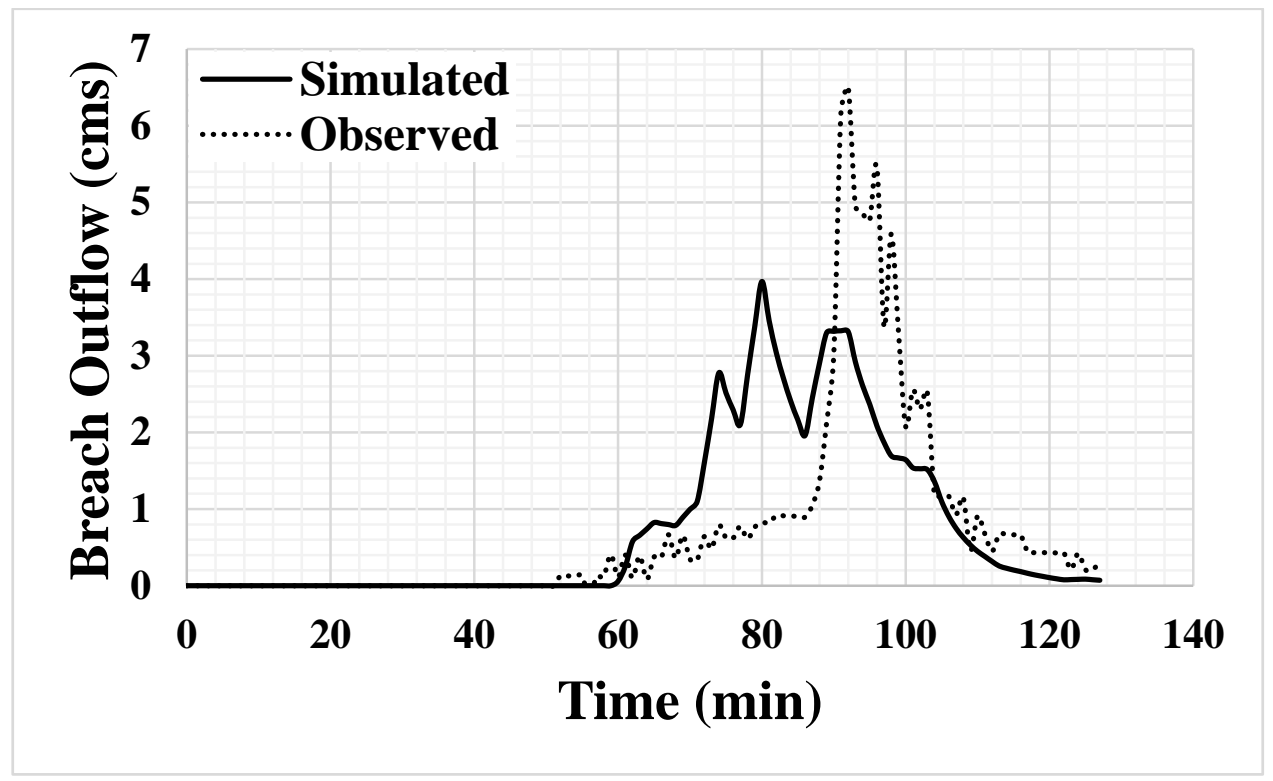

Fig. 4. Predicted and observed breach hydrograph for USDA-ARS laboratory test 


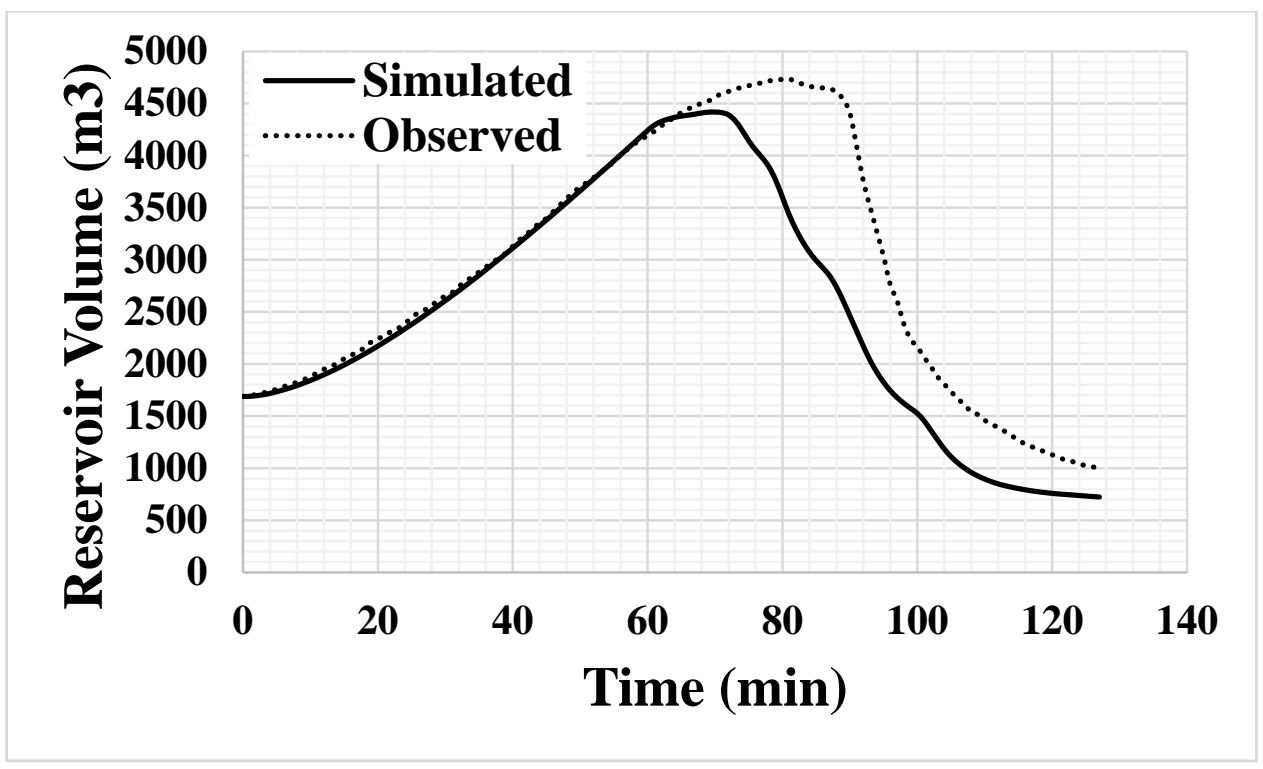

Fig. 5. Predicted and observed reservoir volume for USDA-ARS laboratory test

\subsubsection{Summary of Validation Results}

A summary of model validation results are presented in Table 2. The model efficiency was tested in prediction of breach outflow hydrograph and reservoir volume, in different sizes of dams (2.2- $61 \mathrm{~m})$, wide range of simulation durations (2.5- $398 \mathrm{hrs),} \mathrm{various} \mathrm{progression} \mathrm{types} \mathrm{(linear,} \mathrm{sine} \mathrm{wave} \mathrm{and} \mathrm{user-}$ defined) and two different failure triggers (water surface elevation and initiation time). The model performs excellent for the two large dams, but is not as efficient as these two cases in the case of the small dam. This is because the developed model is not a detailed physically-based model and rather, is a simplified one that is developed particularly for probabilistic applications where extremely long computational time is expected. We acknowledge the limited value of simplified models. However, the main focus of the model development in this study is on the probabilistic part, and in this situation, the computational efficiency is a challenge. For instance, in the first validation case, the computational time was $1.1 \mathrm{~s}$ whereas running HEC-RAS takes $24.7 \mathrm{~s}$ (24 times greater). Although this difference is not great in a deterministic simulation, for a probabilistic model with $10000 \mathrm{MC}$ realizations, it is $65.6 \mathrm{hr}$ faster than the equivalent HEC-RAS model. Using a multi-dimensional physically-based will make this limitation even more critical. In this situation, simplified models are at a distinct advantage. Bearing in mind these computational efficiency requirements and also the excellent performance of the model in the two large dam cases, (which best represents the current case study size class) the deterministic model is extended to probabilistic. This is done by characterizing the uncertain parameters (average breach width, breach formation time, bottom elevation of final breach and reservoir inflow) with PDFs as described in the methodology section.

Table 2. Summary of model validation results 


\begin{tabular}{|c|c|c|c|c|c|c|c|c|c|c|}
\hline \multirow{2}{*}{$\begin{array}{c}\text { Validation } \\
\text { Case }\end{array}$} & \multirow{2}{*}{$\begin{array}{c}\text { Dam } \\
\text { Height } \\
(\mathrm{m})\end{array}$} & \multirow{2}{*}{$\begin{array}{l}\text { Dam } \\
\text { Size }\end{array}$} & \multicolumn{5}{|c|}{ Breach Outflow } & \multicolumn{3}{|c|}{ Reservoir Volume } \\
\hline & & & $\mathrm{R}^{2}$ & NSE & $\mathrm{F}_{\mathrm{Q}}$ & $\mathrm{F}_{\mathrm{T}}$ & Performance & $\mathrm{R}^{2}$ & NSE & Performance \\
\hline 1. ICOLD & 61 & Large & $\begin{array}{l}97.2- \\
97.3 \%\end{array}$ & $97.2 \%$ & $\begin{array}{l}0.99- \\
1.00\end{array}$ & $\begin{array}{l}1.03- \\
1.04\end{array}$ & Excellent & $99.8 \%$ & $\begin{array}{c}99.7- \\
99.8 \%\end{array}$ & Excellent \\
\hline 2. Banqiao & 24.5 & Large & - & - & 0.98 & 0.99 & Excellent & $77.7 \%$ & $77.0 \%$ & Good \\
\hline $\begin{array}{l}\text { 3. USDA- } \\
\text { ARS }\end{array}$ & 2.2 & Small & $44.2 \%$ & $41.4 \%$ & 0.61 & 0.87 & Satisfactory & $83.7 \%$ & $72.7 \%$ & Good \\
\hline
\end{tabular}

\subsection{Validation of the Selected PDFs}

In this subsection, the selected PDFs for the stochastic input are validated against the observations using the Wahl (1998) database (the database that was used to quantify the uncertainty bands of the input parameters). First, the probability of the observed breach parameters for Wahl (1998) database is calculated. The probability of an observed value is calculated as its corresponding frequency in Wahl (1998) database. The calculated probability values are then compared with the statistics (minimum, maximum and mode) of the selected PDF for each breach parameter (i.e., triangular for formation time and average breach width and uniform for bottom height of the final breach). The results of such an analysis are given for formation time in Fig. 6. It is found that a high percentage (greater than 85\%) of the observed probabilities fall inside the selected PDFs. Therefore, it can be concluded that the probabilistic model fits values to the uncertain parameters that are realistic and within the realm of plausibility."

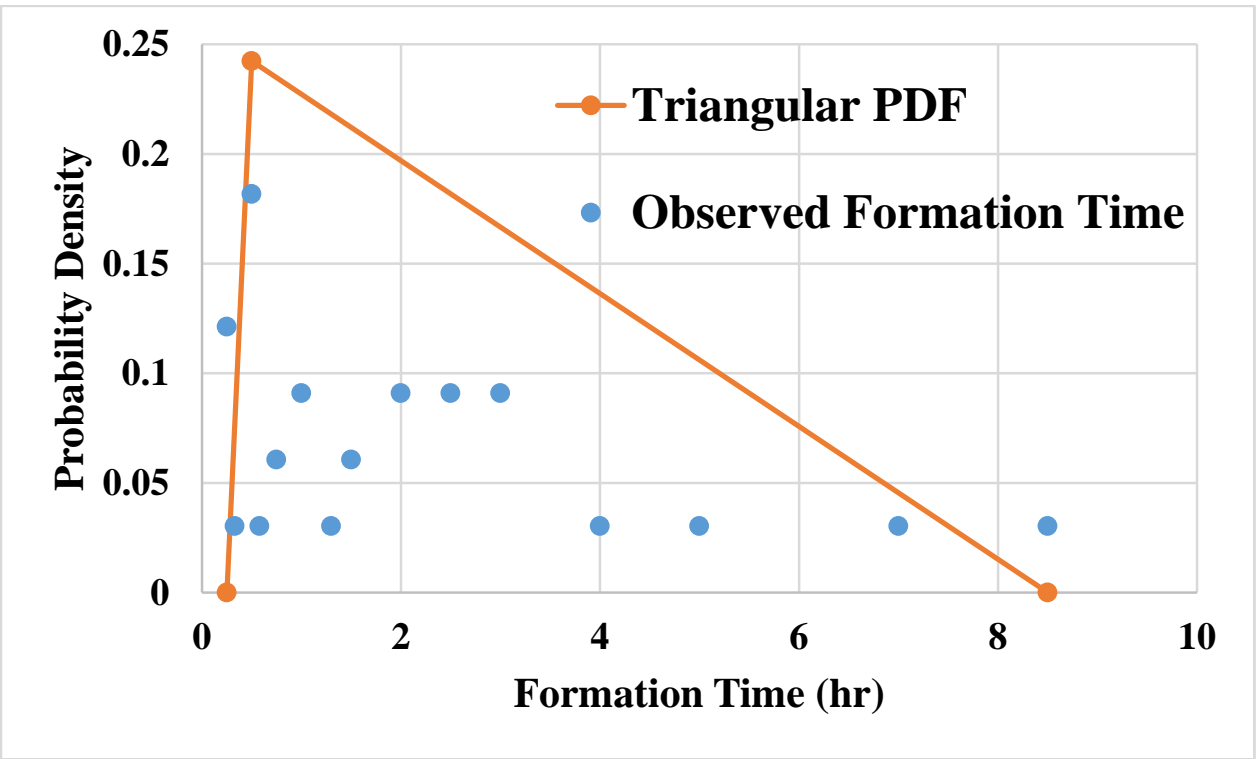

(a) 


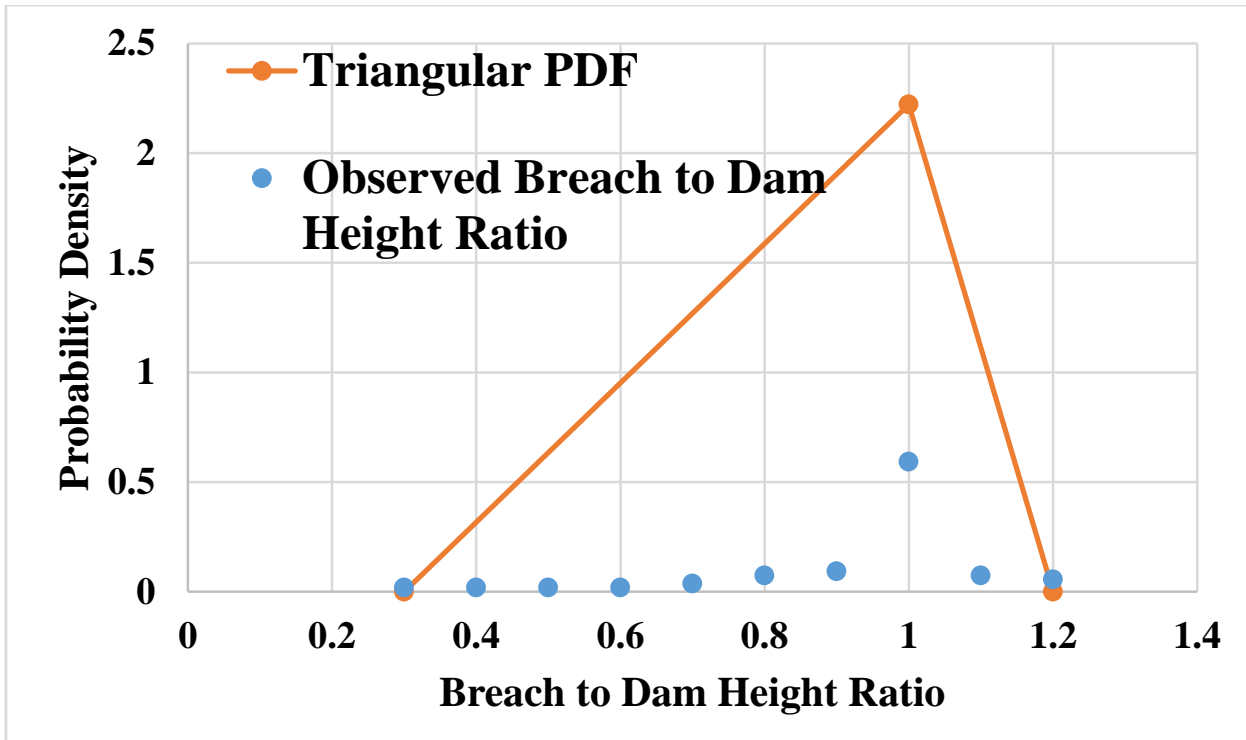

(b)

Fig. 6. Comparison of the selected PDF for the: a) formation time; and b) bottom elevation of final breach with the relative frequency of the reported values in Wahl (1998) database

\subsection{Uncertainty Quantification of the Breach Geometry and Timing}

As noted in the methodology section, average breach width and breach formation time are characterized through PDFs and the statistics of the PDFs are determined through uncertainty analysis. Table 3 shows the widths of uncertainty bands in terms of standard deviation for the four breach prediction methods at 95\% confidence level. The smallest uncertainty bands belong to F95 and VTG in prediction of breach formation time and average breach width, respectively whereas VTG and MLM have the largest uncertainty in estimation of breach formation time and average breach width, respectively.

Table 3. Widths of uncertainty bands of breach prediction methods at 95\% confidence level

\begin{tabular}{ccccc}
\hline Parameter & MLM & VTG & F95 & F08 \\
\hline $\begin{array}{c}\text { Average Breach Width } \\
\text { Breach Formation } \\
\text { Time }\end{array}$ & \pm 0.82 & \pm 0.35 & \pm 0.39 & \pm 0.39 \\
Reference & \pm 0.83 & \pm 0.84 & \pm 0.64 & \pm 0.69 \\
\hline
\end{tabular}

\subsection{Probabilistic Model Validation}

The probabilistic model is applied to the Banqiao Dam failure, which was also used to validate the deterministic model. 10000 LHS realizations are settled for these probabilistic simulations in order to be consistent with the application case study (i.e., Burnett dam). It is tested whether the observed peak (the entire hydrograph time series was not reported for this failure case) falls within the $90 \%$ confidence 
interval of the predicted peak by the probabilistic model. Table 4 shows the $5^{\text {th }}$ and $95^{\text {th }}$ percentiles of the peak alongside the reported peak outflow. According to the table, the reported peak outflow fits within the $5^{\text {th }}$ and $95^{\text {th }}$ percentiles by the probabilistic model. This validation indicates that the probabilistic model predicts reliable breach outflow values.

Table 4. Comparison of the $5^{\text {th }}$ and $95^{\text {th }}$ percentiles with the reported peak values for the Banqiao Dam failure

\begin{tabular}{ccc}
\hline Reported Peak $(\mathrm{cms})$ & Q $_{5 \text { th }}(\mathrm{cms})$ & Q95th $_{\text {(cms })}$ \\
\hline 78100 & 39688 & 109352 \\
\hline
\end{tabular}

A further analysis is to compare the percentiles of the reservoir volume time series against the reported values via the ARIL measure. Fig. 7 shows the $5^{\text {th }}$ and $95^{\text {th }}$ percentiles of the reservoir volume alongside the reported time series. According to the figure, the reported volume time series falls approximately between the $5^{\text {th }}$ and $95^{\text {th }}$ percentiles by the probabilistic model. An ARIL value of 2.0 is also computed, which shows that the model performance is fairly acceptable (Jin et al., 2010). This additional validation indicates that the probabilistic model performs well in prediction of the reservoir volume time series.

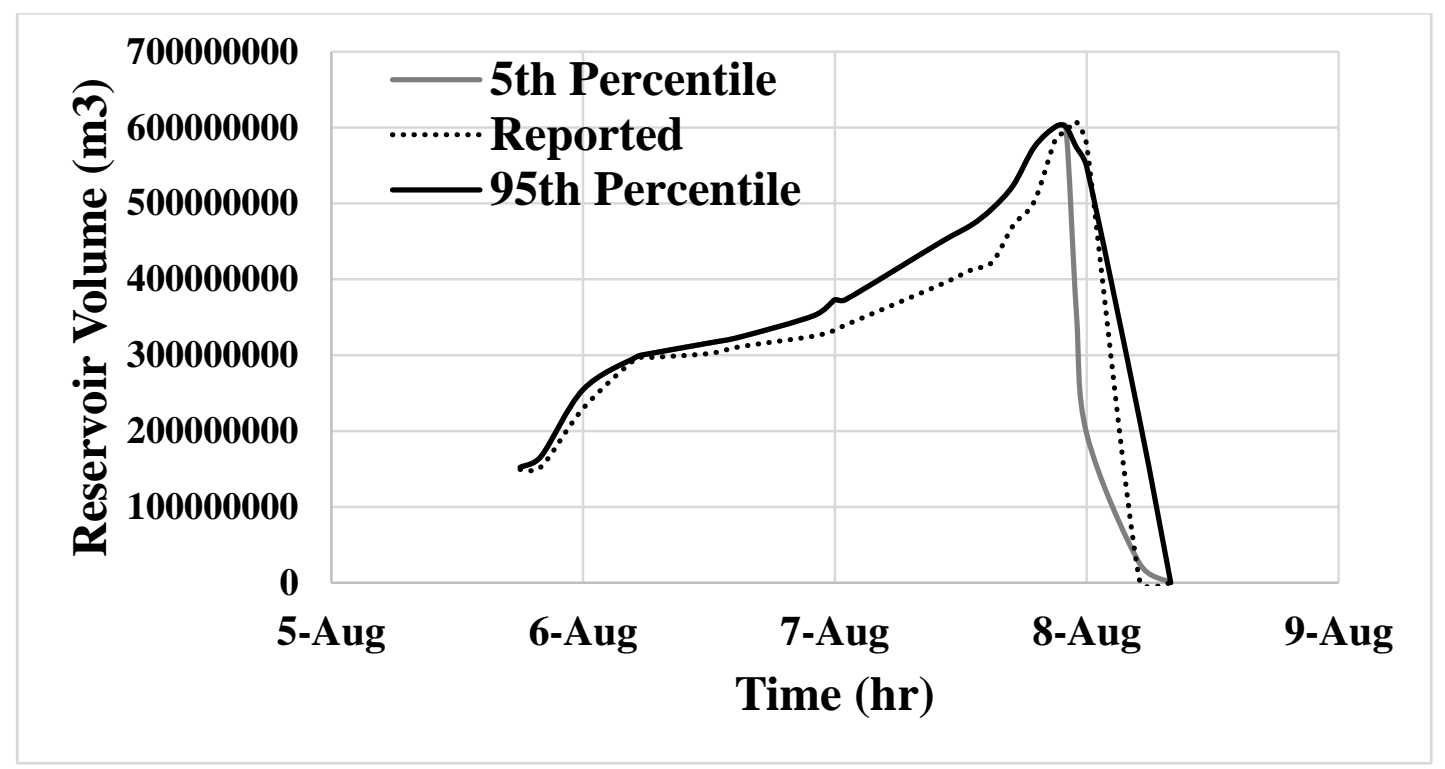

Fig. 7 . The $5^{\text {th }}$ and $95^{\text {th }}$ percentiles along with the reported reservoir volume for the Banqiao Dam failure

\subsection{Probabilistic Model Illustration}

The validated probabilistic dam breach model is illustrated on the case study of Burnett Dam. To set up the model for the case study, the dam characteristics are used along with the inflow data. The statistics for inflow input are obtained based on the data analysis of a US Geological Survey (USGS) gaging station 
upstream of the dam (USGS 0344894205, North Fork near Walkertown, NC). Instantaneous data series (15-min interval) from 1990 to 2013 are used to determine minimum, mean, maximum, standard deviation and autocorrelation coefficient. The highest peak streamflow recorded in the upstream station is $198.2 \mathrm{cms}$ during Hurricane Ivan in September 2004. The flow values are routed from the upstream station using a calibrated channel routing model. Initial volume of water in the reservoir is set to crest elevation (pool elevation of $796.3 \mathrm{~m}$ ) to avoid non-failure scenarios. Based on the Federal Emergency Management Agency (FEMA) (1987), a critical overtopping depth of $0.6 \mathrm{~m}$ is used as the embankment is in good condition with no sign of seepage and settlement. This refers to 26.3 million $\mathrm{m}^{3}$ of volume of water (i.e., $V_{w}$ of 26.3 million $\mathrm{m}^{3}$ ).

The probabilistic dam breach model is run for each of the four prediction methods (MLM, VTG, F95 and F08) using 10000 LHS realizations. It is noteworthy that in some realizations, MLM predicts extremely large breaches, which are unrealistic as they exceed the dam dimensions. To avoid this type of result, a condition is set in the GoldSim ${ }^{\circledR}$ model, in which the maximum average breach width and volume of eroded material cannot exceed dam crest length and total embankment volume, respectively. Running the model with 10-day simulation duration and 10000 realizations of LHS takes about 4.5 hrs and produces about $1.2 \mathrm{~GB}$ of data. The simulations are conducted on a computer with an Intel ${ }^{\circledR} \mathrm{Core}^{\mathrm{TM}}$ i7-4700MQ, 2.40 GHz x64-based Processor with 6 MB Cache, 8 GB Random Access Memory (RAM) and Windows $8^{\mathrm{TM}}$ Operating System.

\subsection{Comparison of the Results}

Mean values and percentiles of the breach parameters and outflow hydrograph attributes generated by the four prediction methods are analyzed in this sub-section. The mean values of beginning time of failure (i.e., beginning time of rising limb in the outflow hydrograph) and bottom elevation of final breach do not vary by using the four prediction methods and thus are not compared here. It is to be noted that time to peak is affected by initial reservoir water surface level. Therefore, the results presented here for time to peak should not be taken as absolute and definitive. A multivariate analysis is also performed to identify the sensitivity of the three hydrograph attributes to average breach width, formation time and bottom elevation of final breach. A detailed discussion is provided in the following sections.

\subsubsection{Comparison of mean values and percentiles}

Mean values alongside $5^{\text {th }}$ and $95^{\text {th }}$ percentiles of average breach width, formation time, time to peak, hydrograph duration and peak outflow estimated by the four prediction methods, are compared in detail in this section.

Average Breach Width: Mean values along with $5^{\text {th }}$ and $95^{\text {th }}$ percentiles of average breach width are presented in Table 5. MLM predicts wider breaches compared to the other methods. Other methods give comparable results with VTG and F95 predicting larger breach widths compared to F08. The reason that 
the F95 method predicts wider breaches than the earlier method is that the exponent of maximum final breach height is nearly five times higher than the F08 method while the exponent of reservoir volume remains same (see Equations 12 and 14).

Similar to the Wahl (2004) study (top of flood space scenario), MLM gives the largest breach in this study. However, VTG and F95 predicts breaches that are very close in size. This is not the same as Wahl (2004), in which Froehlich predicted larger breaches than VTG. This underlies the following reasons: i) in contrast to Froehlich (1995) where reservoir volume is linearly correlated to the average breach width, VTG involves reservoir volume through an offset factor $(B)$ (and not the real volume of the water in the reservoir). Because the reservoir size is larger than $1.23^{*} 10^{7} \mathrm{~m}^{3}$ in both cases, this parameter remains the same as the Wahl (2004) study (see Table 1). However, the reservoir volume of the Wahl (2004) case study is more than 10 times greater than the present study. Thus, a smaller breach by F95 and larger breach by VTG is estimated, compared to Wahl (2004) study; ii) depth of water above breach invert is greater in our study, and as VTG directly uses this parameter, a greater average breach width is predicted as compared to the Wahl (2004) study.

Table 5. Mean value and percentiles of average breach width

\begin{tabular}{cccc}
\hline $\begin{array}{c}\text { Breach Prediction } \\
\text { Method }\end{array}$ & Mean $(\mathrm{m})$ & $5^{\text {th }}$ Percentile $(\mathrm{m})$ & $9^{\text {th }}$ Percentile $(\mathrm{m})$ \\
\hline MLM & 170.2 & 44.0 & 399.0 \\
VTG & 148.3 & 77.1 & 231.3 \\
F95 & 147.4 & 74.5 & 236.8 \\
F08 & 121.4 & 61.7 & 194.5 \\
\hline
\end{tabular}

Breach Formation Time: Table 6 shows the mean values in tandem with $5^{\text {th }}$ and $95^{\text {th }}$ percentiles of breach formation time. The longest mean formation time is estimated by MLM method. This is about 3 times longer than the Froehlich methods. F95 produces comparable results with F08, which estimates the shortest formation time among all the four methods. The reason that F08 predicts slightly shorter formation time than F95 is due to the fact that a smaller and greater exponent is used in F08 equations for $V_{w}$ and $h_{b}$, respectively (see Equations 13 and 15).

The findings on the formation time is different from what was found by Wahl (2004). In Wahl (2004) study (top of flood space scenario), VTG predicted the shortest formation time. However, it gives the second longest formation time in our study. This underlies the fact that the average breach width is larger than Wahl (2004) and formation time is linearly related to average breach width. Additionally, depth of water above breach invert is greater in our study, and the higher this parameter, the shorter the formation time in VTG. Here, Froehlich methods give the shortest formation time, which is because our reservoir 
volume is about 10 times less than the Wahl (2004) case study, and the larger this parameter, the shorter the formation time in Froehlich methods.

Table 6. Mean value and percentiles of breach formation time

\begin{tabular}{cccc}
\hline $\begin{array}{c}\text { Breach Prediction } \\
\text { Method }\end{array}$ & Mean (min) & $5^{\text {th }}$ Percentile (min) & $95^{\text {th }}$ Percentile (min) \\
\hline MLM & 509.6 & 99.6 & 1165.0 \\
VTG & 409.2 & 64.7 & 989.1 \\
F95 & 166.7 & 44.3 & 360.8 \\
F08 & 158.6 & 39.4 & 352.6 \\
\hline
\end{tabular}

Time to Peak: Mean value along with $5^{\text {th }}$ and $95^{\text {th }}$ percentiles of time to peak are given in Table 7 . Using F95 results in the latest peak outflow compared to the others. On other hand, MLM predicts the fastest time to peak, which is due to the large estimated breach, and accordingly high volume of water withdrawn from the reservoir. The predicted values by F08 and MLM are comparable, in which F08 delays the MLM value in mean and $95^{\text {th }}$ percentile, but F08 predicts a faster time to peak in the $5^{\text {th }}$ percentile. The reason that F08 also predicts a fast time to peak is likely due to the short estimated formation time by this method.

Comparing the values of time to peak and formation time (Table 6 andTable 7), it can be concluded that a longer formation time does not inevitably result in a longer time to peak. For example, MLM estimates the longest formation time, while it results in the fastest time to peak. Thus, formation time cannot be solely used to represent time to peak. In other words, a breach prediction method with the shortest formation time, does not necessarily give the fastest time to peak. A dam breach simulation tool should be therefore employed in order to govern hydrograph elements and to choose the breach prediction method with fastest/latest time to peak.

An interesting finding here is that in spite of the remarkable difference in the uncertainty bands in terms of average breach width and formation time for the four methods (see Table 3), the uncertainty bands are very close in terms of time to peak. It is noteworthy that MLM and F95 are the least and most uncertain method in terms of time to peak.

Table 7. Mean value and percentiles of time to peak

\begin{tabular}{ccccc}
\hline $\begin{array}{c}\text { Breach Prediction } \\
\text { Method }\end{array}$ & Mean (min) & $\begin{array}{c}5^{\text {th }} \text { Percentile } \\
(\min )\end{array}$ & $\begin{array}{c}95^{\text {th }} \text { Percentile } \\
(\min )\end{array}$ & $\begin{array}{c}\text { Uncertainty } \\
\text { Band }\end{array}$ \\
\hline MLM & 5803 & 4987 & 6666 & 0.29 \\
VTG & 5896 & 5052 & 6792 & 0.30 \\
F95 & 5915 & 5060 & 6826 & 0.30
\end{tabular}


Breach Hydrograph Duration: Table 8 shows the mean value along with $5^{\text {th }}$ and $95^{\text {th }}$ percentiles of breach hydrograph duration. Using MLM leads to the most elongated outflow hydrograph than the others, which is due to the longer predicted formation time. On the other hand, applying F08 results in the lowest duration for the same reason.

Comparing the values of hydrograph duration and formation time (Table 6 and Table 8), it can be concluded that a longer formation time does not inevitably result in a longer hydrograph duration. For example, F08 estimates the shortest formation time, while it does not result in the shortest hydrograph duration. Thus, formation time cannot be solely used to represent hydrograph duration. In other words, if a breach prediction method with the shortest formation time, does not necessarily give the fastest hydrograph duration. Consequently and similar to what found earlier in time to peak subsection, a dam breach simulation tool should be used to determine hydrograph elements and to choose the breach prediction method with fastest/latest time to peak.

MLM and F95 are the least and most uncertain methods. In opposite to time to peak (see previous subsection), the uncertainty bands are not close in terms of hydrograph duration. Moreover, the degree of uncertainty is higher compared to time to peak.

Table 8. Mean value and percentiles of breach hydrograph duration

\begin{tabular}{ccccc}
\hline $\begin{array}{c}\text { Breach Prediction } \\
\text { Method }\end{array}$ & Mean (min) & $\begin{array}{c}5^{\text {th }} \text { Percentile } \\
(\min )\end{array}$ & $\begin{array}{c}95^{\text {th }} \text { Percentile } \\
(\min )\end{array}$ & $\begin{array}{c}\text { Uncertainty } \\
\text { Band }\end{array}$ \\
\hline MLM & 869.3 & 176.3 & 3013 & 3.26 \\
VTG & 818.5 & 111.0 & 3256 & 3.84 \\
F95 & 591.2 & 68.2 & 2785 & 4.60 \\
F08 & 594.2 & 67.8 & 2789 & 4.58
\end{tabular}

Peak Outflow: Mean value alongside $5^{\text {th }}$ and $95^{\text {th }}$ percentiles of peak outflow are reported in Table 9 . Using F08 leads to the highest peak outflow magnitude. According to the weir equation (which was used to compute the breach outflow), the breach outflow is a function of different parameters. While some of these parameters do not vary with the prediction method (such as breach height), there are three parameters that are functions of prediction method. These parameters are: breach side slope, average breach width and formation time. Steeper side slope, larger breach and faster formation time leads to a higher peak magnitude. Therefore, as F08 predicts the fastest breach growth, a high peak outflow is predicted accordingly. In contrast, applying MLM generates the lowest peak outflow. This is mainly because a very gradual breach formation is predicted by MLM, which in spite of the largest predicted 
breach dimension, results in a lowest peak value among the other methods. Furthermore, the suggested side slope by this method is $0.5(\mathrm{H}: \mathrm{V})$, which is the steepest slope among the four breach prediction methods. Intuitively, the results show that the milder the side slope produces a lower the peak rate.

Comparing the peak magnitudes with average breach and formation time (Table 5 and Table 6), it can be concluded that a shorter formation time results in a greater peak. For instance, F08, with the shortest formation time, produces the greatest peak, and MLM, with the longest formation time, generates the lowest peak.

F95 and VTG are the least and most uncertain methods. In opposite to time to peak and similar to hydrograph duration (see previous subsections), the uncertainty bands are not close in terms of peak. Moreover, the degree of uncertainty is higher comparing to time to peak, but lower comparing to hydrograph duration.

Table 9. Mean value and percentiles of peak outflow

\begin{tabular}{ccccc}
\hline $\begin{array}{c}\text { Breach Prediction } \\
\text { Method }\end{array}$ & Mean $(\mathrm{cms})$ & $\begin{array}{c}5^{\text {th }} \text { Percentile } \\
(\mathrm{cms})\end{array}$ & $\begin{array}{c}95^{\text {th }} \text { Percentile } \\
(\mathrm{cms})\end{array}$ & $\begin{array}{c}\text { Uncertainty } \\
\text { Band }\end{array}$ \\
\hline MLM & 2495 & 720.7 & 6640 & 2.37 \\
VTG & 3492 & 721.4 & 10429 & 2.78 \\
F95 & 6297 & 1577 & 15453 & 2.20 \\
F08 & 6626 & 1600 & 16384 & 2.23 \\
\hline
\end{tabular}

Worst Case Scenarios of the Breach Parameters: Based on the results presented in Table 5 to Table 9 , breach prediction methods that result in the worst case scenario for each of the five parameters is determined. The worst case is defined as the breach with largest geometry, shortest formation time, time to peak and hydrograph duration, and highest peak outflow magnitude. F08 gives the worst scenario in two of the five parameters breach formation time and peak outflow. On the other hand, MLM reflects the worst case in average breach width and time to peak $^{1}$. While F95 gives the worst case scenario of hydrograph duration, it is noteworthy that the values are very close to F08. The worst case method results along with the critical values for each of the five parameters are summarized in Table 10. It is to be mentioned that the results belong to the current case study and cannot be replicated to the other dams.

Table 10. Worst case values for the five parameters and the corresponding breach prediction method

\begin{tabular}{cccccc}
\hline \multirow{3}{*}{ Parameter } & Average & Breach & Time to Peak & Hydrograph & Peak \\
& Breach Width & Formation & $($ min) & Duration (min) & Outflow (cms) \\
& $(\mathrm{m})$ & Time (min) & & & \\
\hline
\end{tabular}

\footnotetext{
${ }^{1}$ It is to be mentioned that MLM gives the most critical value in mean value, but does not return the most crucial value in all percentiles (such as $5^{\text {th }}$ ). F08 leads to the most critical time to peak value in some percentiles.
} 


\begin{tabular}{cccccc}
\hline Mean & 170.2 & 158.6 & 5803 & 591.2 & 6626 \\
$5^{\text {th }}$ Percentile & 44.0 & 39.4 & 4987 & 68.2 & 1600 \\
$95^{\text {th }}$ Percentile & 399.0 & 352.6 & 6666 & 2785 & 16384 \\
\hline $\begin{array}{c}\text { Breach } \\
\text { Prediction }\end{array}$ & MLM & F08 & MLM & F95 & F08 \\
Method & & & & \\
\hline
\end{tabular}

Uncertainty of the Breach Prediction Methods: Based on the results presented in Table 3 and Table 7 to Table 9, the least and most uncertain methods can be identified, which are shown in Table 11. Based on the table, VTG is the least uncertain method in average breach width and hydrograph duration, F95 is least uncertain in formation time and peak outflow, and MLM is least uncertain in time to peak. Hence, a single prediction method cannot be identified as the least/most uncertain method in all the five parameters. Aside from MLM, which is the least uncertain method in time to peak and also gives the most critical value of this parameter, in other four parameters, the method that gives the worst scenario, is not the least uncertain method. For example, F08 that gives the worst scenario of the two parameters, is not the least uncertain method for any of these parameters. On the other hand, VTG, which does not result in any of the worst case scenarios, is the least uncertain method in average breach width and hydrograph duration. In addition, MLM that returns the most critical case of average breach width, is the most uncertain method in this parameter.

Table 11. The least and most uncertain breach prediction methods

\begin{tabular}{cccccc}
\hline Parameter & $\begin{array}{c}\text { Average } \\
\text { Breach Width } \\
(\mathrm{m})\end{array}$ & $\begin{array}{c}\text { Breach } \\
\text { Formation } \\
\text { Time (min) }\end{array}$ & $\begin{array}{c}\text { Time to Peak } \\
(\text { min) }\end{array}$ & $\begin{array}{c}\text { Hydrograph } \\
\text { Duration (min) }\end{array}$ & $\begin{array}{c}\text { Peak } \\
\text { Outflow (cms) }\end{array}$ \\
\hline $\begin{array}{c}\text { Least } \\
\text { Uncertain } \\
\begin{array}{c}\text { Method } \\
\text { Most }\end{array}\end{array}$ & VTG & F95 & MLM & MLM & F95 \\
$\begin{array}{c}\text { Uncertain } \\
\text { Method }\end{array}$ & MLM & VTG & F95 & F95 & VTG \\
\hline
\end{tabular}

\subsubsection{Multivariate Analysis of the Results}

A multivariate analysis is carried out within GoldSim ${ }^{\circledR}$ to investigate the sensitivity of the three breach outflow hydrograph attributes, time to peak, hydrograph duration and peak outflow, to average breach width, formation time and bottom elevation of final breach. Fig. 8 shows the values of importance 
measure for time to peak in the four prediction methods in respect with average breach width, formation time and bottom elevation of final breach. Table 12 shows the $R^{2}$ values for time to peak in the four prediction methods in respect with average breach width, formation time and bottom elevation of final breach.

Time to Peak: Based on Fig. 8 (a), formation time is the most important parameter in all the four methods. Aside from MLM, average breach width is the least important parameter in the other three prediction methods. This implies that the timing characteristic of breach has a greater impact on time to peak than the geometric features in all the prediction methods.

Based on Table 12, there is a weak linear relationship ( $R^{2}$ of less than $3.3 \%$ ) between time to peak with average breach width, formation time and bottom elevation of final breach in all the four methods. Using a multivariate regression of average breach width, formation time and bottom elevation of final breach, a slightly stronger relationship can be found in all methods. However, it is still a weak relationship ( $R^{2}$ of less than $3.7 \%$ ). In general, multivariate linear regression has a slightly stronger $R^{2}$ compared to univariate type for all the four prediction methods.

Breach Hydrograph Duration: Based on Fig. 8 (b), formation time is the most important parameter for impacting hydrograph duration in MLM and VTG. In the other two methods, bottom elevation of final breach is the most important parameter. Likewise, average breach width is the least important parameter in all the four methods. A similar conclusion to what was found for the time to peak cannot be made here as both timing and geometric characteristics of breach closely affect the hydrograph duration.

Based on Table 12, a weak linear relationship ( $R^{2}$ of less than $5.8 \%$ ) with average breach width, formation time and bottom elevation of final breach is found in all the four methods. Nevertheless, this is slightly stronger than what found earlier in time to peak section. Using a multivariate regression of average breach width, formation time and bottom elevation of final breach, a slightly stronger relationship can be found in all the four methods. However, it is still a weak relationship ( $R^{2}$ of less than $8.0 \%$ ). In general, multivariate linear regression has a slightly stronger $R^{2}$ compared to univariate type for all the four prediction methods.

Peak Outflow: Based on Fig. 8 (c), formation time is the most important parameter in all the four breach prediction methods. The values of importance measure are much higher than the two other hydrograph attributes (time to peak and hydrograph duration). Aside from MLM, average breach width is the least important parameter in the other three methods. This is in agreement with what was found for time to peak where timing characteristic of the breach had a greater influence than its geometric properties. This is also in agreement with what discussed earlier on Table 9, in which it was concluded that the shorter the formation time, the greater the peak magnitude. This also justifies why F08 with the shortest formation time yields the highest peak magnitude even though it predicted the smallest breach (see earlier 
discussion on Table 9). A similar conclusion can be derived for MLM that estimates the lowest peak rate with the most gradual formation and largest breach.

Based on Table 12, a fair linear relationship ( $R^{2}$ between $42.6 \%$ to $55.1 \%$ ) with breach formation time is found all the four methods. Using a multivariate regression of average breach width, formation time and bottom elevation of final breach, a stronger relationship can be found in all the four methods.

Comparing to the two timing elements of breach hydrograph, time to peak and hydrograph duration, a much stronger linear relationship is found. In other words, peak outflow can be better described linearly by the breach parameters.

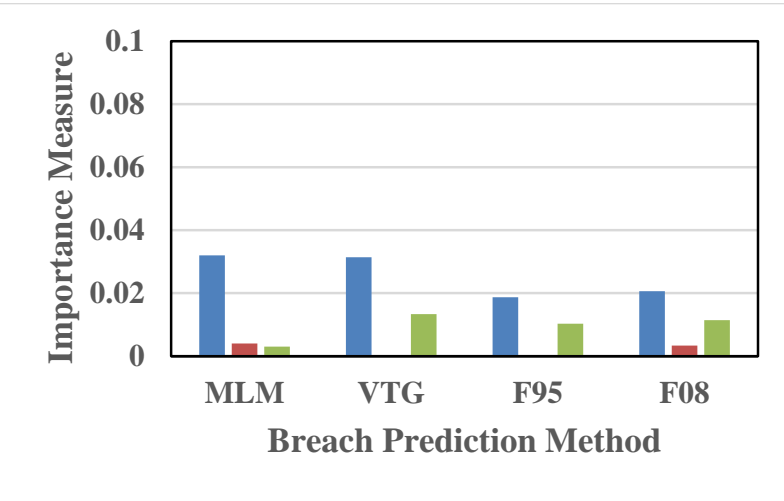

(a)

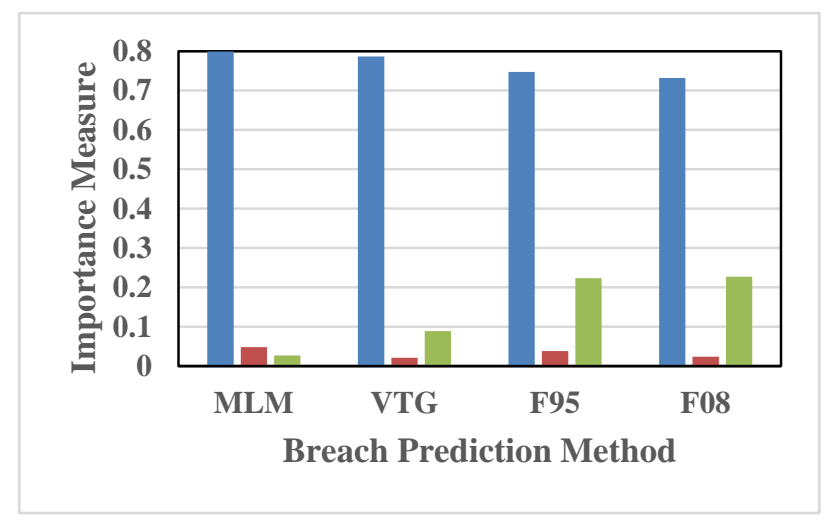

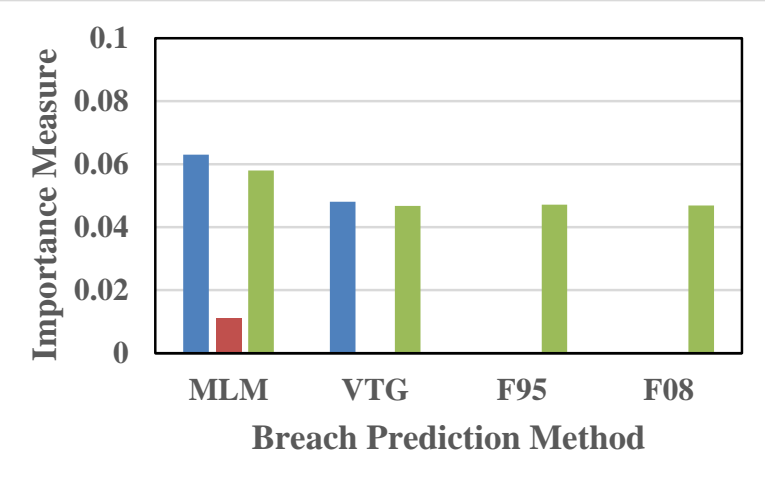

(b)

(c)

Fig. 8. Values of importance measure for: a) time to peak; b) hydrograph duration; and c) peak outflow in the four prediction methods

Table 12. $R^{2}$ values of breach hydrograph attributes in the four prediction methods for both univariate and multivariate analyses

\begin{tabular}{|l|l|l|l|l|}
\hline & Parameter & Time to Peak & Hydrograph Duration & Peak Outflow \\
\hline
\end{tabular}




\begin{tabular}{|c|c|c|c|c|c|c|c|}
\hline $\begin{array}{c}\text { Breach } \\
\text { Prediction } \\
\text { Method }\end{array}$ & & Univariate & Multivariate & Univariate & Multivariate & Univariate & Multivariate \\
\hline MLM & $\begin{array}{c}\text { Breach } \\
\text { Formation } \\
\text { Time } \\
\text { Average } \\
\text { Breach } \\
\text { Width } \\
\text { Bottom } \\
\text { Elevation } \\
\text { of Final } \\
\text { Breach }\end{array}$ & $0.1 \%$ & $3.2 \%$ & $0.0 \%$ & $8.0 \%$ & $3.9 \%$ & $54.6 \%$ \\
\hline VTG & $\begin{array}{c}\begin{array}{c}\text { Breach } \\
\text { Formation } \\
\text { Time }\end{array} \\
\text { Average } \\
\text { Breach } \\
\text { Width } \\
\text { Bottom } \\
\text { Elevation } \\
\text { of Final } \\
\text { Breach }\end{array}$ & 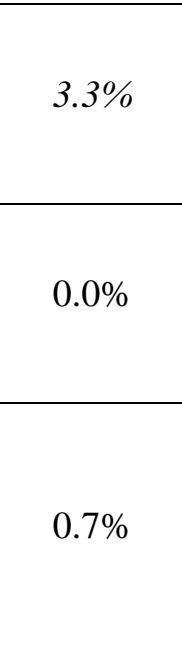 & $3.7 \%$ & 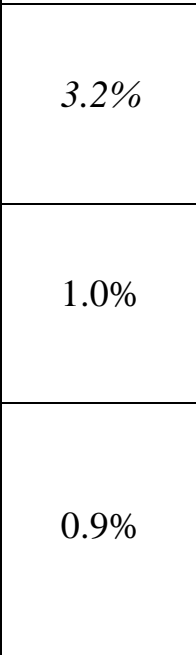 & $4.8 \%$ & $0.4 \%$ & $46.5 \%$ \\
\hline F95 & $\begin{array}{c}\text { Breach } \\
\text { Formation } \\
\text { Time } \\
\text { Average } \\
\text { Breach } \\
\text { Width } \\
\text { Bottom } \\
\text { Elevation } \\
\text { of Final } \\
\text { Breach }\end{array}$ & 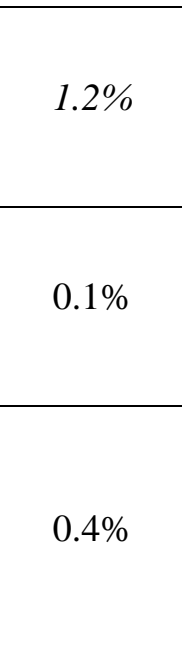 & $1.3 \%$ & $0.1 \%$ & $1.7 \%$ & $55.1 \%$ & $59.8 \%$ \\
\hline
\end{tabular}




\begin{tabular}{|c|c|c|c|c|c|c|c|}
\hline \multirow{3}{*}{ F08 } & $\begin{array}{c}\text { Breach } \\
\text { Formation } \\
\text { Time }\end{array}$ & $1.3 \%$ & \multirow{3}{*}{$1.4 \%$} & $0.1 \%$ & \multirow{3}{*}{$1.6 \%$} & $53.2 \%$ & \multirow{3}{*}{$57.8 \%$} \\
\hline & $\begin{array}{c}\text { Average } \\
\text { Breach } \\
\text { Width }\end{array}$ & $0.0 \%$ & & $0.0 \%$ & & $1.7 \%$ & \\
\hline & $\begin{array}{c}\text { Bottom } \\
\text { Elevation } \\
\text { of Final } \\
\text { Breach }\end{array}$ & $0.5 \%$ & & $1.0 \%$ & & $23.5 \%$ & \\
\hline
\end{tabular}

\section{Future Research Direction}

In this study, four regression-based breach prediction methods were analyzed. Recently, other advanced techniques such as Artificial Neural Networks (ANNs) (e.g., Zagonjolli (2007)) have received more attention in developing breach prediction equations. Evaluating the impact of using these methods on outflow hydrograph characteristics and comparison of the results with regression-based methods will further improve the understanding of dam breach methods. In addition to these methods, the results can be compared with physically-based models such as HR BREACH (Mohamed et al., 2002; Morris et al., 2009a), WinDAM/SIMBA (Temple et al., 2005, 2006; Hanson et al., 2005) and FIREBIRD (Wang et al., 2006) as our developed model has limitations (e.g., soil erodibility and sediment transport) in detailed simulation of breach processes. However, large computational expenses often hinder the application of such detailed models (Westoby et al., 2014).

Four sources of uncertainty were considered in this study. There are other uncertain parameters such as breach side slope, which were not taken into account here. The probabilistic model is capable of handling other uncertainty sources. As a potential research for the future, it is recommended that additional uncertain parameters to be included in the probabilistic analysis. In addition to this, there are intra-model uncertainties such as those arising from the numerical integration method. Although predicting breach characteristics is considered to be the most uncertain step in dam breach simulation (Wahl, 1998; Morris, 2000; Wu et al., 2011), studying the impact of these uncertainty sources is a worthy research topic for the future.

The uncertainty of the four stochastic inputs were characterized by specific PDFs (see Methodology section). Selection of a PDF is a key exercise in the LHS as it reflects parameter uncertainty (Alcamo and Bartnicki, 1987). One limitation of probabilistic dam breach modeling is lack of knowledge about selection of a suitable PDF for breach parameters (Morris, 2000). This can be a source of uncertainty in 
LHS application, which might not be negligible (Zagonjolli, 2007). To address this, other potential PDFs such as uniform distribution should be used and the results should be compared with current findings.

In the breach outflow computation, the methodology of HEC-RAS was followed. Other approaches such as National Weather Service (NWS) FLDWAV (Fread, 1993) can also be employed to analyze the impact of breach outflow equation on the comparative results. In this context, Greimann (2004) concluded that both HEC-RAS and FLDWAV generate identical results for non-submerged flows. However, a similar conclusion was not made for submerged flows. Moreover, the current study is limited to linear breach progression assumption in outflow calculation. Other nonlinear progression types such as sine wave can also be used, which might better reflect slower growth at the beginning and finish of breach formation (Froehlich, 2008).

The development of a probabilistic framework to evaluate dam breach inputs provides a more complete understanding of the uncertainty of the breach outflow hydrograph attributes. This research focuses on a single case, which allows for certain conclusions to be drawn; however, additional case studies using this probabilistic framework will highlight the impact of specific dam geometry and timing on the results of this analysis.

The present study showed the capabilities of probabilistic tools on a numerical iterative dam breach model. This is the first step in dam break risk analysis. The next step will be routing the flow hydrograph through the downstream channel and evaluation of the hazard in the downstream areas. In the future, the authors will evaluate the downstream flood hazard by using a flood model that can be used to further assess the impact of breach prediction method on flood parameters (e.g., depth, velocity, duration, rate of rise and so on) and resultant hazard.

By taking the advantages of the probabilistic dam breach model presented, generalized equations describing outflow hydrograph attributes as function of dam breach parameters can be developed based on findings from the multivariate analysis section. However, to undertake such a task, additional dams with variety of characteristics are needed to be studied. Although such equations have been extensively studied for the peak outflow, timing attributes of the breach hydrograph, which are vital elements in downstream risk assessment (Morris, 2005), have not received any attention yet. Such equations can be potentially utilized in the cases with limited data and where dam breach models are difficult to be developed.

\section{Summary and Conclusions}

A probabilistic dam breach framework was presented in this study to compare four empirical breach prediction methods, including MLM, VTG, F95 and F08. The comparison was performed based on the results of breach parameters (average breach width and formation time) and outflow hydrograph attributes (time to peak, hydrograph duration and peak). A deterministic dam breach model was first developed 
within GoldSim ${ }^{\circledR}$ environment. The model was validated on three overtopping events: i) hypothetical dam proposed by ICOLD; ii) Banqiao Dam in China; and iii) USDA-ARS laboratory test. The validation results revealed acceptable performance of the model. The model was then extended to the probabilistic framework by considering four stochastic elements, including average breach width, breach formation time, bottom elevation of final breach and reservoir inflow. LHS was used as an uncertainty propagation tool in the probabilistic model. The probabilistic model was then validated against a historical failure.

Comparison of the mean values and percentiles showed that F08 produces the critical case in terms of breach formation time and peak outflow while MLM reflects the critical case of average breach width and time to peak, and F95 does so in hydrograph duration. Regarding the uncertainty band, VTG is the least uncertain method in average breach width and hydrograph duration, F95 has the lowest uncertainty bands in terms of formation time and peak outflow, and MLM does so in time to peak. Hence, the method that gives the worst scenario, is not the least uncertain method (aside from MLM, which is the least uncertain method in time to peak and also gives the most critical value of this parameter).

Conducting a multivariate analysis in GoldSim ${ }^{\circledR}$ and using the values of importance measure revealed that breach formation time is the most important parameter in terms of time to peak and peak outflow. However, it cannot be generally taken as the most important parameter in terms of hydrograph duration. On the other hand, average breach width is the least important parameter in terms of all the three hydrograph attributes in all the four methods.

Regression analysis also indicated that there is a very weak linear relationship between breach outflow hydrograph timing attributes with average breach width, formation time and bottom elevation of final breach. In contrast to the timing elements of breach hydrograph, peak outflow can be better described linearly by the breach parameters. In fact, a fair linear relationship between peak outflow with breach formation time is found for all the four prediction methods. Using a multivariate regression (i.e., simultaneous use of average breach width, formation time and bottom elevation of final breach), a stronger relationship can be found in all the four prediction methods compared to univariate type (i.e., sole use of formation time). The regression-based relationships can be potentially utilized for the cases with limited data and where dam breach models cannot be easily developed.

This methodology provides a probabilistic framework for evaluating otherwise very difficult breach parameters to calculate and/or predict. Generally, these parameters are derived deterministically in practice by federal agencies responsible for dam safety (Moran et. al., 2010). For dam breach modeling practitioners, this research provides a guide to better understand which parameters are most critical and pose the greatest variability, and thus require additional sensitivity testing for practical applications using these four breach prediction methods. In addition, this research offers a probabilistic framework for understanding the relationships between common breach parameters and resulting outflow characteristics. 
In the past ten years, USACE has focused on ensuring that its dams do not exceed tolerable risk limits through a USACE-wide portfolio risk management approach (USACE, 2014). Consequence estimations in terms of PAR, economic damages and loss of life are one of the primary outputs of USACE's riskbased approach (Needham et. al., 2010). The probabilistic framework proposed through this research provides a more stochastically-based approach for evaluating the factors that ultimately dictate the severity of the breach hydrograph, which is used to derive economic damages and loss of life estimations. Therefore, it greatly assists dam safety management in development of more reliable emergency action plans (EAPs). It likewise enables a more reliable and rational dam safety decision making process (Krzysztofowicz, 2001; Ahmadisharaf et al., 2016).For this particular case study, the multivariate analysis showed that the importance of individual parameter estimation and the relationships between breach parameter estimations and breach outflow characteristics varies dramatically for the various breach parameter prediction methods. This variability highlighted the need to perform dam breach analyses using a probabilistic framework for practical applications. Only through additional research and case study applications can the uncertainty of breach parameter estimation, which is directly related to consequence estimation, be minimized to an acceptable level.

\section{Acknowledgments}

We are grateful to the financial support by Center of Management, Utilization and Protection of Water Resources. We would also really appreciate the fruitful guidance by William Flower and Nick Martin for helping in development of the dam breach model within GoldSim ${ }^{\circledR}$ environment. Likewise, we truly thank Karl Visser for providing insightful information about the USDA-ARS laboratory test. Special thanks to Michael Gee for providing data and also valuable guidance on the paper.

\section{Notation}

$A R I L=$ average relative interval length;

$B=$ offset factor in VTG breach prediction method;

$B_{\text {avg }}=$ average width of final breach;

$B_{f}=$ final breach width;

$B F F=$ breach formation factor;

$C=$ dam crest width;

$F_{Q}=$ Peak flow accuracy measure;

$F_{T}=$ Travel time accuracy measure;

$g=$ acceleration of gravity;

$h_{b}=$ height of breach;

$h_{w}=$ depth of water above breach at time of failure;

$K_{O}=$ overtopping multiplier in Froehlich breach prediction methods; 
$m=$ breach side slope;

$Q_{b}=$ breach outflow;

$t_{f}=$ breach formation time;

$V_{e r}=$ volume of embankment material eroded;

$V_{w}=$ volume of water that passes through the breach;

$z_{3}=$ summation of slope $(\mathrm{H}: \mathrm{V})$ of upstream and downstream faces of dam;

\section{References}

1. Ahmadisharaf, E., 2016. A coupled probabilistic hydrologic/hydraulic modeling framework to investigate the impacts of hydrograph uncertainty on flood consequences, Ph.D. Dissertation, Tenn. Technol. Univ., Cookeville, TN.

2. Ahmadisharaf, E., Bhuiyan, M.N.M., Kalyanapu, A.J., 2013. Impact of spatial resolution on downstream flood hazard due to dam break events using probabilistic flood modeling, Dam Saf. Conf., ASDSO, Providence, RI, 263-276.

3. Ahmadisharaf, E., Kalyanapu, A.J., 2015. Investigation of the impact of streamflow temporal variation on dam overtopping risk: Case study of a high-hazard dam, World Environ. and Water Resour. Congr., ASCE, Austin, TX. 1050-1057. doi: 10.1061/9780784479162.103.

4. Ahmadisharaf, E., Kalyanapu, A.J., Chung, E.S., 2015. Evaluating the effects of inundation duration and velocity on selection of flood management alternatives using multi-criteria decision making. Water Resour. Manage., 29(8), 2543-2561. doi:10.1016/j.jhydrol.2015.12.031.

5. Ahmadisharaf, E., Kalyanapu, A.J., Chung, E.S., 2016. Spatial probabilistic multi-criteria decision making for assessment of flood management alternatives. J. Hydrol., 533, 365-378. doi:10.1016/j.jhydrol.2015.12.031.

6. Alcamo, J., Bartnicki, J., 1987. A framework for error analysis of a long-range transport model with emphasis on parameter uncertainty, Atmos. Environ., 21(10), 2121-2131, doi:10.1016/00046981(87)90345-3.

7. ASCE, 2013. 2013 report card for America's infrastructure, Available at: <http://www.infrastructurereportcard.org/a/browser-options/downloads/2013-Report-Card.pdf > . (accessed 03.2014.)

8. Beven, K., Binley, A., 1992. The future of distributed models: model calibration and uncertainty prediction. Hydrol. Process., 6, 279-298. doi: 10.1002/hyp.3360060305.

9. Brunner, G.L., 2010. HEC-RAS user's manual, Version 4.1., No. CPD-68, USACE, Hydrologic Engineering Center, Davis, CA.

10. Brunner, G.L., 2014. Using HEC-RAS for dam break studies, No. TD-39, USACE, Hydrologic Engineering Center, Davis, CA. 
11. CEATI, 2008. Embankment dam erosion and breach project, No. T032700\#0207B.

12. Dang, N.M., Babel, M.S., Luong, H.T., 2011. Evaluation of food risk parameters in the Day River flood diversion area, Red River delta, Vietnam. Nat. Hazards, 56(1), 169-194. doi: 10.1007/s11069010-9558-x.

13. Dotto, C.B.S., Mannina, G., Kleidorfer, M., Vezzaro, L., Henrichs, M., McCarthy, D.T., Freni G., Rauch W., Deletic, A., 2012. Comparison of different uncertainty techniques in urban stormwater quantity and quality modelling. Water Res., 46(8), 2545-2558.

doi:10.1016/j.watres.2012.02.009.FEMA, 1987. Risk-based approach to dam safety assessment, FEMA/Stanford University Workshop Notes, Denver, CO.

14. Fread, D.L., 1991. BREACH, an erosion model for earthen dam failures, Office of Hydrology, NWS, Silver Spring, MD.

15. Fread, D.L., 1993. NWS FLDWAV model: The replacement of DAMBRK for dam-break flood prediction, Dam Saf., ASDSO, Kansas City, MO.

16. Froehlich, D.C., 1995. Embankment dam breach parameters revisited, Water Resour. Eng., ASCE, New York, NY.

17. Froehlich, D.C., 2008. Embankment dam breach parameters and their uncertainties, J. Hydraul. Eng., 134(12), 1708-1721, doi:10.1061/(ASCE)0733-9429(2008)134:12(1708).

18. Gee, D.M., Brunner, G.W., 2007. Comparison of breach predictors, Dam Saf., ASDSO, Austin, TX.

19. Gilroy, K.L., McCuen, R.H., 2012. A nonstationary flood frequency analysis method to adjust for future climate change and urbanization, J. Hydrol., 414, 40-48, doi:10.1016/j.jhydrol.2011.10.009.

20. Greimann, B.P., 2004. Comparison between the methods used in MIKE11 2003, FLDWAV 1.0, and HEC-RAS 3.1.1 to compute flows through a dam breach, US Department of the Interior, Bureau of Reclamation, Technical Service Center, Sedimentation and River Hydraulics Group.

21. Hall, J.W., Tarantola, S., Bates, P.D., Horritt, M.S., 2005. Distributed sensitivity analysis of flood inundation model calibration, J. Hydraul. Eng., 131(2), 117-126, doi:10.1061/(ASCE)07339429(2005)131:2(117).

22. Hanson, G.J., Cook, K.R., Hunt, S.L., 2005. Physical modeling of overtopping erosion and breach formation of cohesive embankments. Trans. ASABE, 48(5), 1783-1794.

23. Helton, J.C., Davis, F.J., 2003. Latin hypercube sampling and the propagation of uncertainty in analyses of complex systems, Reliab. Eng. Syst. Saf., 81(1), 23-69, doi:10.1016/S09518320(03)00058-9.

24. Hirabayashi, Y., Mahendran, R., Koirala, S., Konoshima, L., Yamazaki, D., Watanabe, S., Kim, H., Kanae, S., 2013. Global flood risk under climate change, Nature Clim. Change, 3(9), 816-821, doi:10.1038/nclimate1911. 
25. Janssen, H., 2013. Monte-Carlo based uncertainty analysis: Sampling efficiency and sampling convergence, Reliab. Eng. Syst. Saf., 109, 123-132, doi:10.1016/j.ress.2012.08.003.

26. Jin, X., Xu, C. Y., Zhang, Q., Singh, V. P., 2010. Parameter and modeling uncertainty simulated by GLUE and a formal Bayesian method for a conceptual hydrological model. J. Hydrol., 383(3), 147155. doi:10.1016/j.jhydrol.2009.12.028.

27. Kalyanapu, A.J., Shankar, S., Stephens, A., Judi, D.R., Burian, S.J., 2011. Assessment of GPU computational enhancement to a 2D flood model, Environ. Modell. Software, 26(8), 1009-1016, doi:10.1016/j.envsoft.2011.02.014.

28. Krzysztofowicz, R., 2001. The case for probabilistic forecasting in hydrology. J. Hydrol., 249 (1), 29. doi:10.1016/S0022-1694(01)00420-6.

29. Kuo, J.T., Yen, B.C., Hsu, Y.C., Lin, H.F., 2007. Risk analysis for dam overtopping-Feitsui reservoir as a case study. J. Hydraul. Eng., 133(8), 955-963. doi: 10.1061/(ASCE)07339429(2007)133:8(955).

30. Kwon, H.H., Moon, Y.I., 2006. Improvement of overtopping risk evaluations using probabilistic concepts for existing dams. Stochastic Env. Res. Risk Assess., 20(4), 223-237. doi: 10.1007/s00477005-0017-2.

31. MacDonald, T.C., Langridge-Monopolis, J., 1984. Breaching characteristics of dam failures, J. Hydraul. Eng., 110(5), 567-586, doi:10.1061/(ASCE)0733-9429(1984)110:5(567).

32. Mallakpour, I., Villarini, G., 2015. The changing nature of flooding across the central United States, Nat. Clim. Change, 5, 250-254, doi:10.1038/nclimate2516.

33. Massey, F.J., 1951. The Kolmogorov-Smirnov Test for goodness of fit, J. Am. Stat. Assoc., 46(253), 68-78, doi:10.1080/01621459.1951.10500769.

34. McKay, M.D., Beckman, R.J., Conover, W.J., 1979. Comparison of three methods for selecting values of input variables in the analysis of output from a computer code, Technometrics, 21(2), 239245, doi:10.1080/00401706.1979.10489755.

35. Melching, C.S., 1995. Reliability estimation, in: Singh, V. P. (Ed.), Computer models of watershed hydrology. Water Resources Publications, Littleton, CO.

36. Mohamed, M.A.A., Samuels, P.G., Morris, M.W., Ghataora, G.S., 2002. Improving the accuracy of prediction of breach formation through embankment dams and flood embankments, Int. Conf. on Fluvial Hydraul. (River Flow), Louvain-la-Neuve, Belgium.

37. Moran, B.P., Margo, D.A., Seda-Sanabria, Y., 2010. Modeling, Mapping, and Consequence (MMC) Production Center - efforts supporting critical infrastructure, Annual United States Society on Dams (USSD) Conf., USSD, Sacramento, CA, 461-475.

38. Morris, M.W., 2000. CADAM concerted action on dambreak modelling, Rep. SR 571. 
39. Morris, M.W., 2005. IMPACT, investigation of extreme flood processes and uncertainty,

40. Morris, M.W., Kortenhaus, A., Visser, P.J., 2009a. Modeling breach initiation and growth. FLOODsite Rep. T06-08-02, FLOODsite Consortium, Available at: <www.floodsite.net>. (accessed 10.2013.).

41. Morris, M.W., Hassan, M.A.A.M., Kortenhaus, A., Visser, P.J., 2009b. Breaching processes: A state of the art review, FLOODsite Rep. T06-06-03, FLOODsite Consortium, Available at: <www.floodsite.net>. (accessed 10.2013.).

42. Nash, J., Sutcliffe, J.V., 1970. River flow forecasting through conceptual models Part I-A discussion of principles, J. Hydrol., 10(3), 282-290, doi:10.1016/0022-1694(70)90255-6.

43. Needham, J.T., Seda-Sanabria, Y., Bowles, D.S., 2010. Consequence estimation for critical infrastructure risk management, Annual USSD Conf., USSD, Sacramento, CA, 477-491.

44. Nelsen, R.B., 2007. An introduction to Copulas, Springer, New York, NY.

45. Peng, M., Zhang, L.M., 2012. Analysis of human risks due to dam-break floods—part 1: a new model based on Bayesian networks, Nat. Hazards, 64(1), 903-933, doi:10.1007/s11069-012-0275-5.

46. Pierce, M.W., Thornton, C.I., Abt, S.R., 2009. Predicting peak outflow from breached embankment dams. J. Hydrol. Eng., 15(5), 338-349. doi: 10.1061/(ASCE)HE.1943-5584.0000197.

47. Qi, H., Altinakar, M.S., 2011a. A GIS-based decision support system for integrated flood management under uncertainty with two dimensional numerical simulations. Environ. Modell. Software, 26(6), 817-821. doi: 10.1016/j.envsoft.2010.11.006.

48. Qi, H., Altinakar, M.S., 2011b. Simulation-based decision support system for flood damage assessment under uncertainty using remote sensing and census block information. Nat. Hazards, 59(2), 1125-1143. doi: 10.1007/s11069-011-9822-8.

49. Qi, H., Altinakar, M.S., 2012. GIS-based decision support system for dam break flood management under uncertainty with two-dimensional numerical simulations. J. Water Resour. Plan. Manag., 138, 334-341. doi: 10.1061/(ASCE)WR.1943-5452.0000192.

50. Ralston, D.C., 1987. Mechanics of embankment erosion during overflow, National Conf. on Hydraulic Eng., ASCE, Reston, VA, 733-738.

51. Saltelli, A., Tarantola, S., 2002. On the relative importance of input factors in mathematical models Safety assessment for nuclear waste disposal, J. Am. Stat. Assoc., 97(459), 702-709, doi:10.1198/016214502388618447.

52. Schubert, J.E., Sanders, B.F., 2012. Building treatments for urban flood inundation models and implications for predictive skill and modeling efficiency. Adv. Water Resour., 41:49-64, doi:10.1016/j.advwatres.2012.02.012. 
53. Singh, V.P., Scarlatos, P.D., 1988. Analysis of gradual earth-dam failure, J. Hydraul. Eng., 114(1), 21-42, doi:10.1061/(ASCE)0733-9429(1988)114:1(21).

54. Temple, D.M., Hanson, G.J., Neilsen, M.L., Cook, K.R. 2005. Simplified breach analysis model for homogeneous embankments: Part 1, Background and model components. Annual USSD Conf., USSD, Denver, CO.

55. Temple, D.M., Hanson, G.J., Neilsen, M.L., 2006. WinDAM - Analysis of overtopped earth embankment dams, American Society of Agricultural and Biological Engineers (ASABE) Annual International Meeting, ASABE, Portland, OR.

56. Thames, B.A., Kalyanapu, A.J., 2013. Assessment of ICOLD Benchmark Case Study using Flood2DGPU and HEC-FIA, Int. Benchmark Workshop on Numer. Anal. of Dams. ICOLD, Zenz, G., Goldbruber, M. (Eds.), Graz, Austria.

57. Thornton, C.I., Pierce, M.W., Abt, S.R., 2010. Enhanced predictions for peak outflow from breached embankment dams. J. Hydrol. Eng., 16(1), 81-88. doi: 10.1061/(ASCE)HE.1943-5584.0000288.

58. Tsakiris, G., Spiliotis, M., 2013. Dam-breach hydrograph modelling: An innovative semi-analytical approach, Water Resour. Manage., 27(6), 1751-1762, doi:10.1007/s11269-012-0046-9.

59. Tung, Y. 2011. Uncertainty and reliability analysis in water resources engineering. J. Contemp. Water Res. Educ. 103(1), 13-21.

60. USACE, 1979. Recommended guidelines for safety inspection of dams. ER 1110-2-106, Washington, DC. Available at:

<http://www.mde.state.md.us/assets/document/damsafety/COE/Guidelines\%20for\%20Safety\%20Insp ections\%20of\%20Dams.pdf>. (accessed 03.2015.).

61. USACE, 1997. Engineering and design - Hydrologic engineering requirements for reservoirs. EM 1110-2-1420, Washington, DC. Available at: <http://planning.usace.army.mil/toolbox/library/EMs/em1110.2.1420.pdf> (accessed 03.2015)

62. USACE, 2013. National Inventory of Dams (NID), Available at: <http://geo.usace.army.mil/pgis/f?p=397:5:0::NO>. (accessed 05.2014.).

63. USACE, 2014. USACE Dam Safety Program, Available at: <http://www.usace.army.mil/Missions/CivilWorks/DamSafetyProgram/ProgramActivities.aspx>. (accessed 05.2014.).

64. Von Thun, J.L., Gillette, D.R., 1990. Guidance on breach parameters.

65. Wahl, T.L., 1998. Prediction of embankment dam breach parameters - A literature review and needs assessment. Dam Safety Rep. DSO-98-004, US Department of the Interior, Bureau of Reclamation, Denver, CO. 
66. Wahl, T.L., 2004. Uncertainty of predictions of embankment dam breach parameters, J. Hydraul. Eng., 130(5), 389-397, doi:10.1061/(ASCE)0733-9429(2004)130:5(389).

67. Wahl, T.L., Hanson, G.J., Courivaud, J.R., Morris, M.W., Kahawita, R., McClenathan, J.T., Gee, D.M., 2008. Development of next-generation embankment dam breach models, Annual USSD Conf., USSD, Portland, OR, 767-779.

68. Wang, Z., Bowles, D.S., 2006. Three-dimensional non-cohesive earthen dam breach model. Part 1: Theory and methodology. Adv. Water Resour., 29(10), 1528-1545, doi:10.1016/j.advwatres.2005.11.009.

69. Washington State Department of Ecology, 2007. Dam safety guidelines Technical note 1 Dam break inundation analysis and downstream hazard classification, Olympia, WA.

70. Westoby, M.J., Glasser, N.F., Brasington, J., Hambrey, M.J., Quincey, D.J., Reynolds, J.M., 2014. Modelling outburst floods from moraine-dammed glacial lakes. Earth Sci. Rev., 134, 137-159. doi:10.1016/j.earscirev.2014.03.009.

71. Wu, W., Altinakar, M.S., Bradford, S.F., Chen, Q.J., Constantinescu, S.G., Duan, J.G., Gee, D.M., Greimann, B., Hanson, G., Zhiguo, H., Hegedus, P., Van Hoestenberghe, T., Huddleston, D., Hughes, S.A., Imran, J., Yafei, J., Jorgeson, J.D., Kahawita, R., Klumpp, C.C., Yong, L., Langendoen, E.J., Shielan, L., Moreda, F., Morris, M.W., Morvan, H., Orendorff, B., Pak, J., Peeters, P., Reed, S., Sanders, B.F., Scott, S.H., Soares-Frazo, S., Song, C.R., Sutherland, J., Teal, M.J., Tsubaki, R., Wahl, T.L., Weston, D.M., Williams, D.T., Zech, Y., Zhang, L., 2011. Earthen embankment breaching, J. Hydraul. Eng., 137(12), 1549-1564, doi:10.1061/(ASCE)HY.1943-7900.0000498.

72. Xu, Y., Zhang, L.M., 2009. Breaching parameters for earth and rockfill dams, J. Geotech. Geoenviron. Eng., 135(12), 1957-1970, doi:10.1061/(ASCE)GT.1943-5606.0000162.

73. Yochum, S.E., Goertz, L.A., Jones, P.H., 2008. Case study of the big bay dam failure: Accuracy and comparison of breach predictions, J. Hydraul. Eng., 134(9), 1285-1293, doi:10.1061/(ASCE)07339429(2008)134:9(1285).

74. Zagonjolli, M., 2007. Dam break modelling, risk assessment and uncertainty analysis for flood mitigation, Ph.D. Dissertation, Delft Univ. of Technol., Delft, Netherlands.

75. Zhong, D., Sun, Y., Li, M., 2011. Dam break threshold value and risk probability assessment for an earth dam, Nat. Hazards, 59(1), 129-147, doi:10.1007/s11069-011-9743-6. 